\title{
Processing of Biobased Resources
}

\author{
Myriam Loeffler, Jörg Hinrichs, Karin Moß, Marius Henkel, \\ Rudolf Hausmann, Andrea Kruse, Nicolaus Dahmen, \\ Jörg Sauer, and Simon Wodarz
}

The fundamental idea behind the bioeconomy is processing of biobased resources into a wide range of products in the food, feed, energy, and material sectors. Due to the special characteristics of biobased resources (see Sect. 5 . 1), appropriate conversion approaches need to be selected with the desired application in mind.

Food supply is the most traditional and, of course, most essential function of biobased resources. Section 7.1 presents fundamental knowledge on food quality and food processing techniques.

The original online version of this chapter was revised. An erratum to this chapter can be found at https://doi.org/ 10.1007/978-3-319-68152-8_13.

Individual section's authors are indicated on the corresponding sections.

\section{Loeffler ( $\square)$}

Institute of Food Science and Biotechnology; Food Physics and Meat Science, University of Hohenheim, Stuttgart, Germany

e-mail: myriam.loeffler@uni-hohenheim.de

\section{J. Hinrichs}

Institute of Food Science and Biotechnology; Soft Matter Science and Dairy Technology, University of Hohenheim, Stuttgart, Germany

e-mail: j.hinrichs@uni-hohenheim.de

\section{K. Moß • M. Henkel • R. Hausmann}

Institute of Food Science and Biotechnology, Bioprocess Engineering, University of Hohenheim, Stuttgart, Germany
For production of materials, our economic system is predominantly based on finite fossil carbon resources, such as natural gas, crude oil, and coal. Crude oil is the basis for most fuels and is refined into more useful products such as naphtha, gasoline, diesel, asphalt, heating oil, kerosene, and gas. These are further processed to intermediates and final products including plastics, fibers, vanishes, and adhesives. Petroleum (or naphtha) is a liquid raw material consisting of reduced hydrocarbons which are mostly oxidized to the desired product. In this

e-mail: karin.moss@uni-hohenheim.de; marius. henkel@uni-hohenheim.de; Rudolf.Hausmann@unihohenheim.de

\section{A. Kruse}

Institute of Agricultural Engineering; Conversion Technologies of Biobased Resources, University of Hohenheim, Stuttgart, Germany

e-mail: Andrea_Kruse@uni-hohenheim.de

\section{N. Dahmen • J. Sauer • S. Wodarz}

Institute of Catalysis Research and Technology, Karlsruhe Institute of Technology, Karlsruhe, Germany e-mail: nicolaus.dahmen@kit.edu; j.sauer@kit.edu; simon.wodarz@kit.edu 
process, inorganic, often metallic, catalysts are used and both high temperatures and pressures are applied. The conversion starts with pure and relatively concentrated educts, making product recovery comparatively simple.

Biorefinery concepts explore possible routes for the refining of renewable resources to fuels, energy, and materials, analogous to chemical refining processes. These generally make use of all biomass components, resulting in various educt streams which can be converted to basic products. In contrast to crude oil, naphtha, and other petrochemical fractions, biomass materials for biorefineries display lower energy densities, are solid rather than liquid, and are partially oxidized.

Lignocellulose is the most abundant biopolymer and is a solid raw material. It consists of three main components, namely the carbohydrates cellulose and hemicellulose (polyoses) and lignin. Cellulose and hemicellulose are polymers consisting of hexoses and pentoses; lignin is a cross-linked phenolic polymer built up from aromatic alcohols.

Fractionation and depolymerization are prerequisites for further bioconversion. Lignin is most often separated from the carbohydrates and combusted to supply the bioconversion process energy. The carbohydrates can be depolymerized by acid or enzymatic hydrolysis, to form aqueous sugar solutions with a sugar content of about $0.2-2 \%$, which is then concentrated. In this approach, the structure of the resource is preserved, to give relatively defined sugar streams. These sugar streams may be used in biotechnological processes to supplement the substrates sucrose and glucose originating from sugarcane, sugar beet, and hydrolysis of starch (Sect. 7.2).

Another concept is the thermochemical conversion (Sect. 7.3) of the renewable feedstock, which is technologically less demanding. This method breaks down the biomass into a complex mixture of partly reduced substances.

The sugar and lignin fractions are partially oxidized and, in many cases, have to be reduced to gain valuable products. For this purpose, $\mathrm{CO}_{2}$ has to be removed from the carbon skeleton. This implies that on a mass base product yields generally are lower than in petrochemical production. For these reactions, catalysts have to be employed which act highly specifically and stop at a certain oxidative step. Biocatalysts (whole cells or enzymes) possess these properties but, in contrast to inorganic catalysts, they require physiological conditions. The reactions are performed at moderate temperature $\left(10-60{ }^{\circ} \mathrm{C}\right)$, under normal pressure. But as the educt stream is yet diluted, also the product stream is diluted, consisting of only $1-10 \%$ of the product, and 90-99\% of water. This demands a quite intensive downstream processing.

In a biobased economy renewable feedstocks, thus mainly plants, form the basis for materials. Biorefineries provide concepts for thermochemical and biochemical conversion of biobased materials towards fuels, materials, and energy. However, for mobility and energy solutions solar, wind, or geothermal energy are promising, but for materials the use of renewable feedstocks is the most suitable solution so far. Carbon capture and utilization technologies potentially may be included in the biorefinery concepts. 


\subsection{Food Processing}

Myriam Loeffler and Jörg Hinrichs

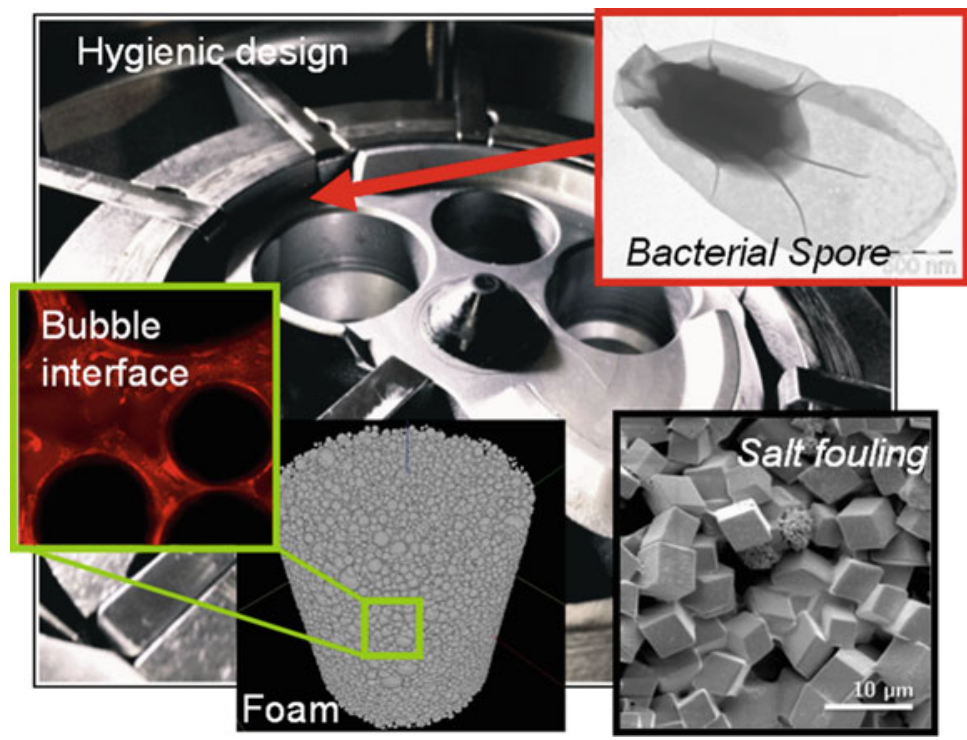

(C) Jörg Hinrichs \& Horst Neve

\begin{abstract}
Food science and technology is the science that deals with the physical, biological, and chemical processes relevant for the processing of food and food ingredients. The goal is to research, develop, and optimize technical procedures based on natural and engineering sciences as well as socioeconomic factors in order to provide high-quality and safe food for human consumption. Food processing refers to the conversion/transformation of raw materials to a safe food product. This chapter introduces the physical, chemical, and biological unit operations typically used in food processing to ensure food safety and quality. The influence of intrinsic as well as extrinsic parameters on microbial growth behavior is highlighted and examples of important factors that need to be considered during food processing are introduced (water activity, enzyme activity, lipid oxidation). At the end of the chapter, strategies for new product developments are also presented.
\end{abstract}

Keywords Food quality; Food safety; Shelf life; Industrial processing; Food functionality; Water activity; Product development

\section{Learning Objectives}

After studying this chapter, you should

- Be familiar with food components and ingredients.

- Know basic processes used in food processing and drivers of technical food processing.

- Be aware of aspects, important for the development of new food products.

\subsubsection{Food and Food Ingredients}

The word "food" refers to substances and products that are taken in by humans through the mouth for the purpose of nutrition and/or pleasure. For this reason, the term also includes 
products that one normally wouldn't think of as foods, such as:

- Alcoholic beverages

- Food ingredients such as salt and spices

- Food additives such as thickeners

- Food supplements such as minerals and vitamin preparations

Major food ingredients (the big five) are:

- Water

- Proteins (Fig. 7.1)

- Fat (Fig. 7.2)

- Carbohydrates (e.g., the monosaccharide glucose, disaccharide lactose, and polysaccharides cellulose and starch)

- Minerals (e.g., calcium, iron, magnesium, zinc)

\section{Minor components/micronutrients are:}

- Vitamins (fat- or water soluble)

- Other functional components

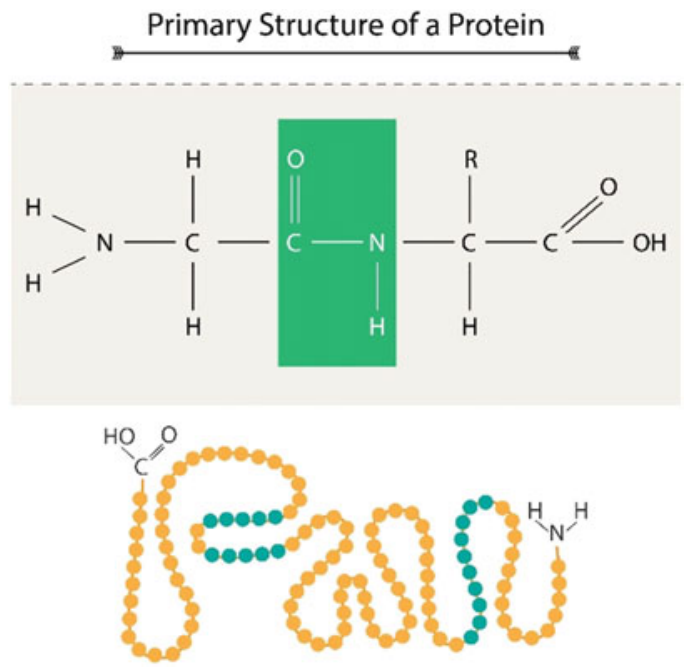

Fig. 7.1 Protein structure; green: peptide bond-linking amino acids

\subsubsection{Unit Operations of Food Processing}

For the consumer, food does not merely give the feeling of satiety (energy) and supply micronutrients, but it provides a pleasurable experience through aroma, taste, color, and texture. Moreover, ritual functions (e.g., the Eucharist) and prohibitions (e.g., Jewish food regulations) are linked to food and food consumption. Nowadays, quite a few of these prohibitions can be explained and understood by looking at former climatic and hygienic conditions and the related diseases. For instance, it is well known that beans should not be consumed without processing. Raw beans contain a toxic protein (phasin), which has to be denatured prior to consumption by heating or pickling to prevent intestinal colic. Thus, knowledge of the cultivation, storage, preservation, and processing of food was and still is of great importance. In this context, food processing describes the conversion/transformation of raw material to a safe food product.

Today, there is a variety of possibilities (e.g., unit operations) to convert and hence process plant and animal raw materials to semifinished goods (e.g., flour), ready-to-eat end products (e.g., bread), and convenience food including special diets.

A distinction has to be made between physical, biological, and chemical methods used for raw material and food processing. Depending on the requirements, these techniques may be applied individually, in a particular order or in combination. Table 7.1 gives an overview of unit operations used in food processing. Most of these techniques were developed a long time ago and then adapted to different food matrices. A few, such as irradiation, have been introduced much more recently. 
Fig. 7.2 Structure of glycerol, saturated and unsaturated fatty acids, and triglycerides
Glycerol

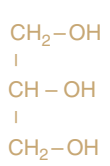

Fatty acids

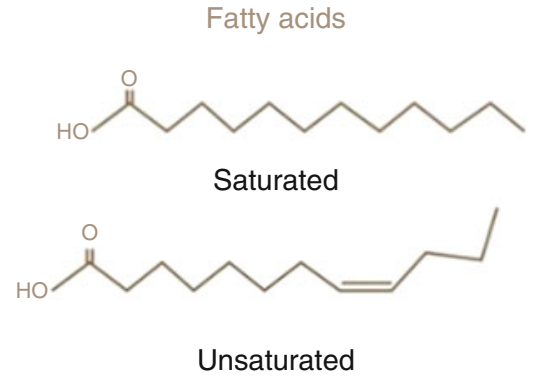

Triglycerides

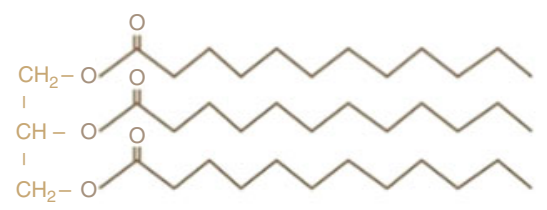

Saturated

Glycerol + 3 fatty acids

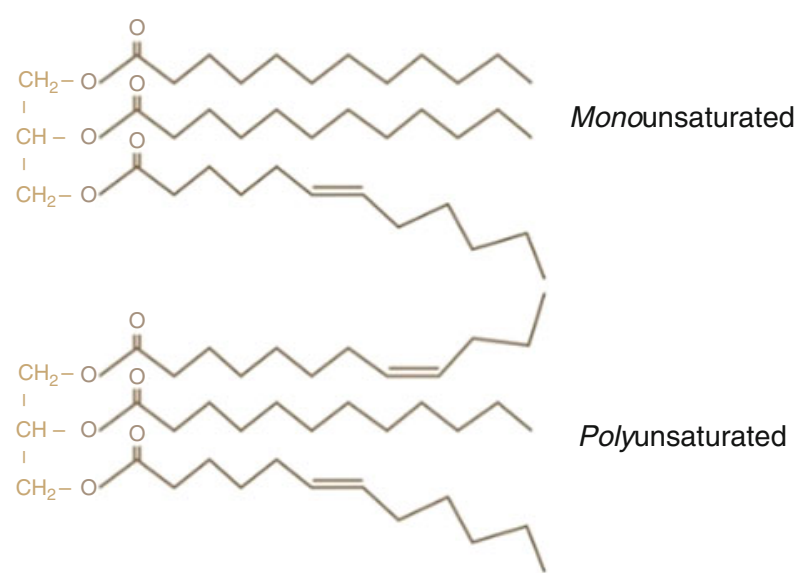

With the beginning of industrialization in the second half of the eighteenth century, major technical advances were made in crop and plant cultivation, food processing, and packaging. For instance, research findings of Justus Liebig led to an increase in agricultural production of about $90 \%$ between 1873 and 1913. The use of fertilizers, scientifically based animal breeding, and initial mechanization of agriculture allowed more and more people to be supplied with food. At the same time, new methods of preservation and packaging were developed (e.g., 1804, sterilization of milk) to extend storage time and improve food transportation, leading to a marked increase in small-scale and large-scale operating companies in Europe and North America.

\subsubsection{Food Quality, Shelf Life, and Food Safety: Drivers of Technical Food Processing}

An important requirement for the storage and trade of food and food ingredients is that they either retain their specific properties (best case) or undergo only minor physicochemical and/or microbial changes over a longer period of time, thus guaranteeing food quality and safety. 
Table 7.1 Examples of food processing objectives classified by main principle and listing of unit operations applied

\begin{tabular}{|c|c|c|}
\hline Main principle & Objective & Unit operation \\
\hline \multirow[t]{7}{*}{ Physical } & $\begin{array}{l}\text { Removal of dirt and unwanted } \\
\text { components }\end{array}$ & Washing, sieving, peeling \\
\hline & Crushing & Cutting, grinding, crushing \\
\hline & Enrichment of certain components & $\begin{array}{l}\text { Pressing, separating, filtering, distilling, extracting, } \\
\text { evaporation, drying, crystallization }\end{array}$ \\
\hline & Texture alteration & Kneading, dispersing, emulsifying, foaming \\
\hline & Shelf life & $\begin{array}{l}\text { Heating, cooling, freezing, drying, microwave heating, } \\
\text { irradiation, high pressure }\end{array}$ \\
\hline & $\begin{array}{l}\text { Destroying interfering or toxic } \\
\text { substances }\end{array}$ & Blanching, cooking \\
\hline & $\begin{array}{l}\text { Improved digestibility, formation of } \\
\text { aromas, browning }\end{array}$ & Heating, frying, cooking, steaming \\
\hline \multirow[t]{2}{*}{ Biological } & $\begin{array}{l}\text { Raw material transformation } \rightarrow \text { taste, } \\
\text { smell, texture }\end{array}$ & $\begin{array}{l}\text { Fermentation, fermentative acidification, enzymatic } \\
\text { reactions }\end{array}$ \\
\hline & Shelf life & Fermentation, acidification \\
\hline \multirow{4}{*}{$\begin{array}{l}\text { Chemical/ } \\
\text { biochemical }\end{array}$} & Taste and texture & Addition of salt or/and sugar \\
\hline & Shelf life & $\begin{array}{l}\text { Addition of salt, sugar, or acid, smoking, addition of } \\
\text { preservatives }\end{array}$ \\
\hline & $\begin{array}{l}\text { Destroying/inactivation of interfering } \\
\text { or toxic substances }\end{array}$ & Acidification, heating \\
\hline & Optical appearance & Addition of colorants \\
\hline
\end{tabular}

"Safe" in this context means that neither pathogens nor toxins are present in the food product prior to consumption. Many of the physical, biological, and chemical methods listed in Table 7.1 are used to prolong shelf life, but they may vary depending on the product. In the past, food products were often preserved by reducing water activity (Sect. 7.1.5) or through fermentation. For instance, foods already traded in antiquity included dry products such as salt, sugar, cereals, dried meat, and spices, or fermented products such as wine or vinegar, as well as saltconserved products including fish (e.g., salt cod), meat, and cheese. Therefore, salt became an important commodity a long time ago, since it was essential for food preservation and seasoning.

\subsubsection{Factors Affecting Microbial Growth}

As our foods are of animal and/or plant origin, it is important to consider the raw material and product characteristics that may influence microbial growth during harvesting, food processing, and (short/long-term) storage.

\section{Intrinsic Parameters (Examples)}

1. $p H$

Microorganisms can be classified according to the minimum, optimum (best growth requirements), and maximum $\mathrm{pH}$ values, at which they can grow. For certain food products, knowing the $\mathrm{pH}$ is of vital importance. For instance, yoghurt ( $\mathrm{pH} 4.3-4.7)$ and fruit juices $(\mathrm{pH} 3.5-3.8)$ have a very low $\mathrm{pH}$ and are therefore mainly spoiled by yeasts and molds, while emulsified sausages have higher $\mathrm{pH}$ values ( 5.9-6.2) and are very prone to contamination with food spoilage-(e.g., pseudomonads) or food-poisoning bacteria (e.g., Listeria monocytogenes).

\section{Moisture content}

The preservation of foods by drying is achieved by the removal or binding of moisture, without which microorganisms are not able to grow. See also water activity in Sect. 7.1.5.

3. Oxidation-reduction potential $(O / R, E h)$

Aerobic microorganisms such as Bacillus ssp., as well as most molds and yeasts, require positive Eh values (oxidized) for growth, whereas 
anaerobes such as Clostridium botulinum require negative Eh values (reduced). However, it should be noted that a lot of bacteria are facultative anaerobes and are thus able to grow under either aerobic or anaerobic conditions.

4. Nutrient content

Nutrient requirements for microbial growth include water, a source of energy (e.g., sugars), a source of nitrogen (e.g., proteins), vitamins and related growth factors, as well as minerals (Sect. 7.1.1). The requirements differ depending on the strain. Generally, Grampositive bacteria are known to have the highest requirements.

5. Antimicrobial constituents

Naturally occurring antimicrobials include for instance lysozyme (eggs, milk) and the lactoperoxidase system (bovine milk).

\section{Extrinsic Parameters (Examples)}

Extrinsic parameters also play a crucial role in microbial growth.

\section{Temperature}

This includes processing temperature and storage temperature.

Here it should be noted that microorganisms can also be classified according to their growth temperatures:

- Psychrotrophs (optimum: $20-30{ }^{\circ} \mathrm{C}$; grow well at or below $7{ }^{\circ} \mathrm{C}$; e.g., Pseudomonas ssp.)

- Mesophiles (optimum: 30-40 ${ }^{\circ} \mathrm{C}$; grow well above $20{ }^{\circ} \mathrm{C}$ and below $45^{\circ} \mathrm{C}$, e.g., Escherichia coli $\mathrm{O} 157: \mathrm{H} 7)$

- Thermophiles (optimum: $55-65{ }^{\circ} \mathrm{C}$; grow well at and above $45^{\circ} \mathrm{C}$, e.g., Streptococcus thermophilus)

\section{Other parameters}

Other extrinsic parameters that should be considered are relative humidity of the environment and the presence of gases (e.g., $\mathrm{CO}_{2}$ ) and/or other microorganisms that produce, e.g., substances that are inhibitory or even lethal to other microorganisms (e.g., bacteriocins, organic acids).

\subsubsection{Special Features of the Industrial Processing of Food}

The general principles and requirements of industrial scale food processing do not differ from homemade, small-scale processing - they usually involve the raw materials, a recipe, and the necessary equipment. In all cases, the end product is expected to be safe and to have a high sensory quality with regard to flavor, taste, color, and texture. Some products may have further requirements such as health aspects. In the food industry, all these requirements are the responsibility of the manufacturer and once products are on the market they are subjected to state quality standard monitoring.

In general, industrial scale food production is characterized by a higher degree of automation. In addition, a "higher" safety level is required, since the semifinished or final products are often marketed over long distances, which in turn requires a longer shelf life and appropriate packaging. In cases where quality deficiency or damage is identified, the recall of industrial scale products is much more difficult than for locally marketed products.

\subsubsection{Raw Materials}

The following factors are of particular importance for technical food production:

- The bulk of raw materials used are of natural plant or animal origin. They have a great variability with respect to composition, autochthone microorganism flora, and processing properties.

- The availability of many raw materials (e.g., fruits, sugar beet, wine) is limited by seasonality.

- Plant raw materials (e.g., coffee, soy, hops) are often only cultivated in certain regions, leading to long transport distances.

- Raw materials are not always available in unlimited supply and their storage is only possible for a limited period of time.

- High price fluctuations are possible. 
- Once processing has been started, it usually cannot be stopped.

Today, other socioeconomic aspects related to the selection of raw materials are taken into account. These are often described by terms such as "resource-conserving," "organic," "eco," "GMO-free," "climate-neutral," and "fair trade." However, as discussed below, these are of minor importance with respect to food processing.

\subsubsection{Processing of Raw Materials}

In the next step, the raw materials are converted into standardized (quality attributes and/or functional properties) products through various unit operations. For this reason, the chemical, biological, and physical properties of the raw materials and also their behavior during processing have to be taken into account. The technology-structure-function relationship behind the processing of raw materials (e.g., sugar beet, milk) into foodstuffs (sugar cubes, processed cheese) is illustrated in Fig. 7.3. In the figure, "technology" includes the substances and ingredients used, their concentration and composition, as well as the basic operation (s) applied (Table 7.1). The desired functionality of the product is achieved through the choice of process parameters (e.g., pressure, temperature, $\mathrm{pH}$ ). The structure of the final product (e.g., sugar cubes: small crystals in the form of a cube of defined edge length, white, solid) is predominantly influenced by the technology used. In turn, the structure provides the basis for the functionality of certain food products (e.g., sugar cubes: dissolve rapidly in hot liquids; desired sweetness).

For the same raw material, even small changes in the process parameters of basic operations, the use of other machines/equipment, or a change in the order of the unit operations can influence the structure and thus also the functionality of the end product. This may or may not be advantageous for the application in question. The functionality includes subjectively and objectively measurable properties of the final product. Nowadays these properties are generally divided into techno-functionality (e.g., shelf life, texture, color, taste, smell, foam formation, emulsion formation) and bio-functionality (e.g., nutritional value, or health aspects).

\subsubsection{Toolbox Used in Food Processing}

Food science and technology deals with the physical, biological, and chemical processes relevant for the processing of food and food ingredients. The goal is to research, develop, and optimize technical procedures based on natural and engineering sciences as well as on socioeconomic factors in order to provide high-quality and safe food for human nutrition. As it is not possible to give an in-depth account of all the factors that need to be taken into account, a few selected important examples are presented here.

\section{Water Activity}

As shown in Table 7.1, various unit operations can be used, for which a wide range of machines and equipment are available. The physical properties (e.g., liquid/solid), the chemical composition, and, in particular, the water content of the raw materials to be processed are of high importance. However, it is freely available water rather than the total water content that is crucial for appropriate processing. Figure 7.4 shows the intensity of various reactions depending on the water activity. The water

Fig. 7.3 Technology-

structure-function relationship for the processing of food as well as the development of new food products

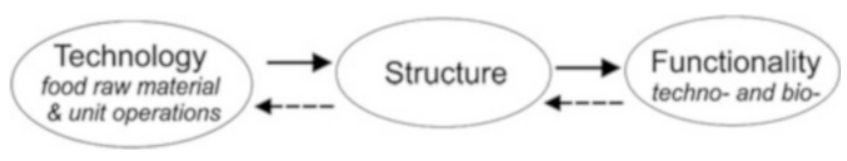


Fig. 7.4 Potential of microorganisms to grow on food depending on water activity (above). Potential shelf life of food and processed food under certain storage conditions (below)

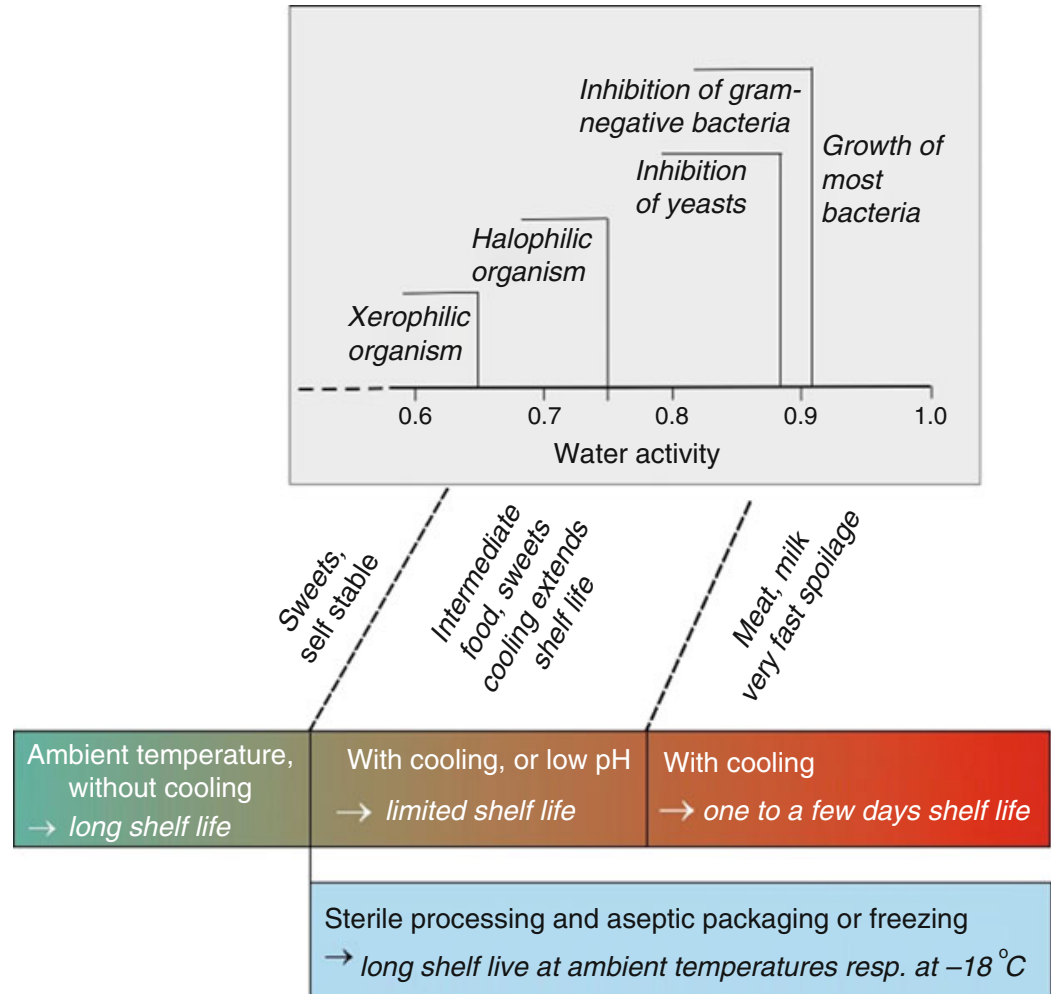

Table 7.2 Water activity of various food raw materials and food products

\begin{tabular}{|l|l|}
\hline Water activity & Food raw material, food products \\
\hline$\geq 0.98$ & Fish, meat, milk, egg, vegetables, juices, fruit, yoghurt, fresh cheese, soft cheese \\
$0.95-0.97$ & Sausages, semihard and hard cheese \\
\hline $0.86-0.92$ & Raw sausage, raw ham, salami, parmesan \\
\hline $0.80-0.90$ & Jam, cakes, bread, syrup, sweetened condensed milk, flour, rice, ketchup \\
\hline $0.70-0.80$ & Soups, marzipan, dry fruit cakes, dried plums, jam of higher concentration \\
\hline $0.60-0.70$ & Honey, nougat, raisins, muesli, nuts, confectionery, dried fruit \\
\hline 0.5 & Pasta, spices \\
\hline 0.4 & Egg powder \\
\hline 0.3 & Cookies \\
\hline 0.2 & Milk powder \\
\hline
\end{tabular}

activity $\left(a_{\mathrm{w}}\right)$ value is calculated as the water vapor pressure of the raw material/foodstuff divided by the vapor pressure of pure water at the same temperature. Substances of low molecular mass, such as salts or sugars, are surrounded by water molecules and can thus reduce the water vapor pressure above the food and therefore also the $a_{\mathrm{w}}$ value.

If the water activity is very close to 1 (Table 7.2), the product is very prone to microbial spoilage, especially if cold storage is insufficient. Accordingly, all raw materials of animal origin must be processed quickly, unless they have their own protective mechanism (such as eggs). The unit operations, drying and salt addition (Table 7.1), can reduce the $a_{\mathrm{w}}$ value (Table 7.2, raw sausage). Freezing also reduces the mobility of water, preventing microorganisms from growing and reducing the rate of chemical reactions. Consequently, this 


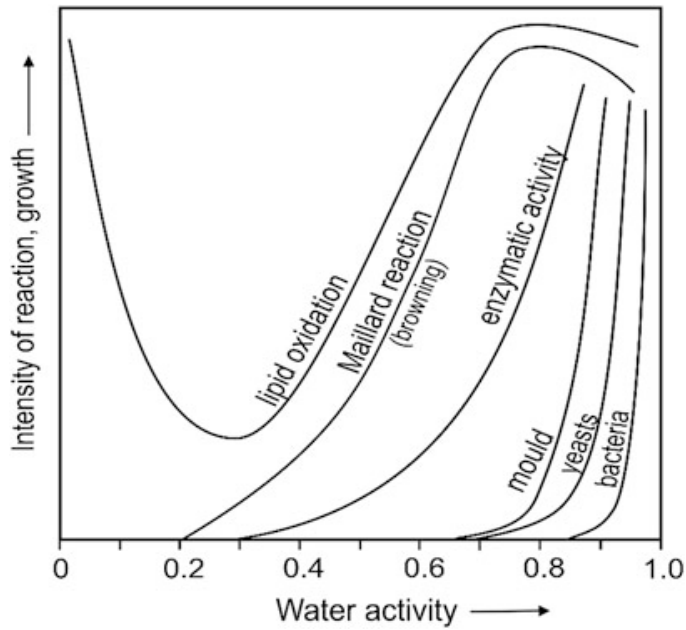

Fig. 7.5 Qualitative description of the intensity of chemical and biochemical reactions, as well as microbial growth, depending on water activity

process is now widely used to protect raw materials, semifinished products, and finished products from spoilage and to preserve vitamins, color, and texture. Many other reactions that also affect food quality, such as lipid oxidation, are directly related to water activity, as demonstrated in Fig. 7.5.

\section{Enzyme Activity, Lipid Oxidation}

As can be seen from Fig. 7.5, enzymatic reactions can be expected until a very low water activity of 0.4 is reached. Therefore, raw materials must be treated in such a way that existing enzyme activities do not lead to undesired changes in sensory properties, color, or texture. One way to prevent enzyme activity and kill microorganisms at the same time is through heating. However, heating can lead to nonenzymatic browning by the Maillard reaction. The reaction takes place between proteins and sugars and may cause desired (caramel, bread, malt beer) or undesired (juices, milk powder) effects depending on the characteristics of the food product.

It is interesting to note that the oxidation of lipids (fats) is lowest at a water activity of 0.2 (minimum) and more pronounced in products with either a lower $\left(a_{\mathrm{w}}<0.2\right)$ or a higher water activity $\left(a_{\mathrm{w}}>0.2\right)$. Thus, fat-containing egg powder and products with many unsaturated fatty acids can only be protected from lipid oxidation by appropriate packaging materials, a protective modified atmosphere without oxygen, or antioxidants. Figure 7.5 and Table 7.2 provide relevant information on some of the unit operations mentioned above necessary for the fulfilment of requirements regarding shelf life, safety, and preservation of the sensory properties of a food product.

\section{Thermal Treatment}

One of the most important unit operations is the thermal treatment of food (Table 7.1). Thermal treatments can improve food safety through killing pathogenic germs and viruses and prolong shelf life by killing spoilage organisms and inactivating enzymes already present in the product and microbial enzymes. However, it should be noted that (intensive) heat treatments may also destroy thermolabile vitamins and accelerate chemical reactions including the Maillard reaction mentioned above.

\section{Example: Milk Production}

Raw milk is an easily perishable foodstuff since it has a near-neutral $\mathrm{pH}$ and a water activity close to 1 (Table 7.2). It was recognized as early as the nineteenth century that raw milk can contain pathogenic microorganisms and is capable of transmitting diseases to humans.

It is therefore a legal requirement that raw milk obtained directly from the producer has to be boiled prior to consumption. However, boiling milk at $100{ }^{\circ} \mathrm{C}$ is not a very gentle treatment and can have a negative effect on its components.

\section{Pasteurization}

It is well known that Mycobacterium tuberculosis (discovered by Robert Koch in 1882, disease: tuberculosis) is one of the most thermostable pathogens in raw milk. For that reason, M. tuberculosis was used to define heating requirements for the pasteurization of milk. Figure 7.6 gives a summary of heat-based methods for the inactivation of pathogenic organisms. Short- 
Fig. 7.6 Kinetics of some example reactions associated with milk heating (Stoeckel et al. 2016)

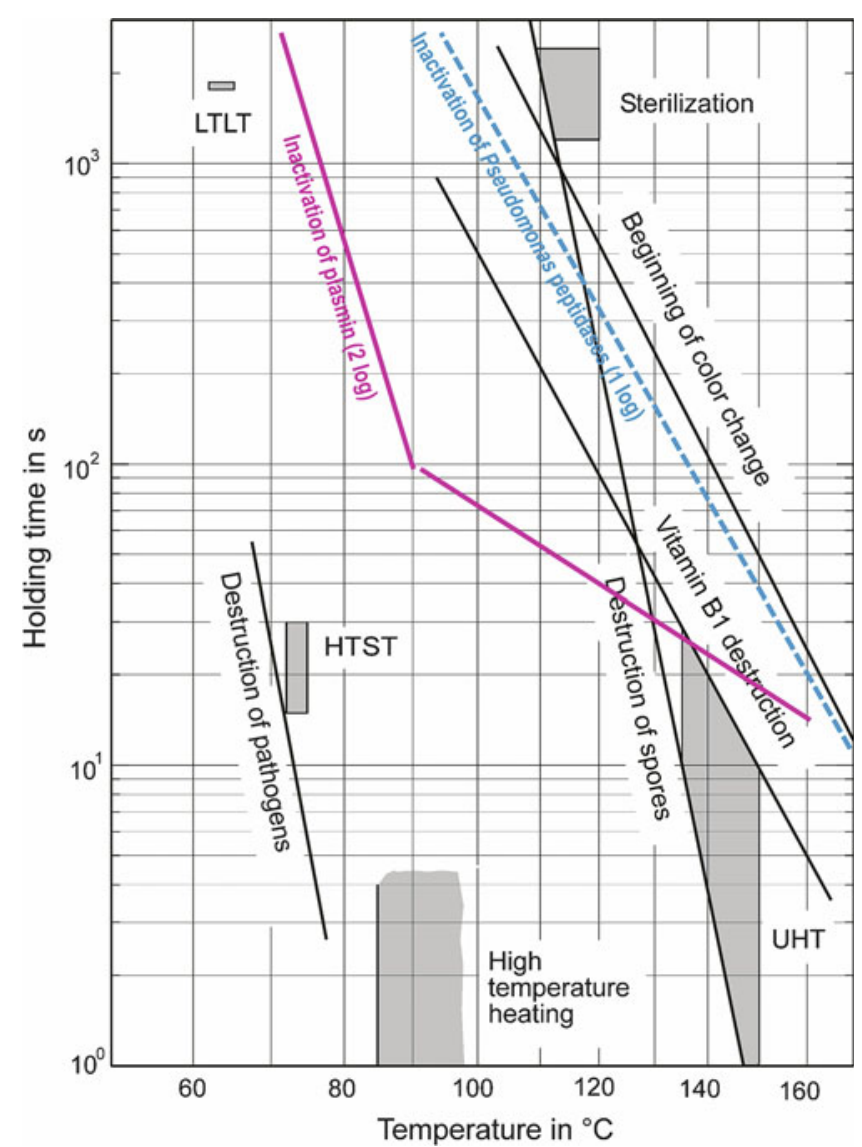

time pasteurization at $72-75{ }^{\circ} \mathrm{C}$ for $15-30 \mathrm{~s}$ provides a safe product with a shelf life of max. 10 days when stored at $<8{ }^{\circ} \mathrm{C}$. Longer is not possible because bacterial spores (extremely resistant, help bacteria to survive extreme conditions) are not sufficiently killed during pasteurization.

\section{Sterilization}

Sterilization is carried out following a traditional process developed by Apert in 1804. The milk is filled into cans or bottles, sealed, and then heated in an autoclave (Fig. 7.6). An autoclave is a pressure vessel in which temperatures of about $120{ }^{\circ} \mathrm{C}$ are reached using overpressure. If this temperature is maintained for about $20-30 \mathrm{~min}$, mesophilic and thermophilic bacterial spores are inactivated. Sterilized milk has a shelf life of 1 year and can be stored at room temperature.
However, the treatment is not very gentle. The heating area for sterile milk (Fig. 7.6) is above the line for visible browning (Maillard reaction) and above the line that marks lysine (an essential amino acid) and vitamin B1 (thiamine) losses.

\section{UHT}

It was not until 1952 that the process of ultrahightemperature heating (uperization) was developed by Alpura (Switzerland). In this process, the milk is heated to about $145{ }^{\circ} \mathrm{C}$ in just a few seconds, kept hot for a few seconds, and then rapidly cooled down again. The heating area used for UHT milk (Fig. 7.6) lies below the line for lysine and vitamin B1 losses but above the spore inactivation line. UHT milk is thus comparable to sterilized milk with regard to shelf life, but the method is more favorable with regard to the components. 


\subsubsection{Complexity of the Technologies Needed to Produce Different End Products from the Same Raw Material}

\section{Example: Products from Tomatoes}

All final products mentioned in Fig. 7.7 are semifinished products (e.g., ketchup, sauces, soup), which are used in households as products or as ingredients for food preparation.

The raw material "tomato" has to be selected and controlled in terms of variety, taste, color, texture, and maturity, with the functionality of the end product in mind.

Immediately after delivery, the tomatoes are washed, sorted, and then further processed using various operations and machines. For instance, after peeling, the tomatoes are filled directly into cans, to which tomato concentrate and, in some cases, also salt are added for better preservation of the tomatoes' structure for subsequent sterilization in the autoclave at $95{ }^{\circ} \mathrm{C}$. Alternatively, peeled tomatoes are passed through sieves (pulp) or chopped (cubes) and then canned and sterilized.

\section{Box 7.1 Process-Indicated Diagrams}

Process-indicated diagrams are usually used in which the unit operations are named as process steps and delimited by a framework of substances (raw materials and additives, ingredients, intermediate products, and end products). Just as the process parameters, the chemical, physical, and (micro) biological properties of the substances that are important for the production process are given as "set points."

During processing, the substances are regularly analyzed and the process parameters then automatically logged ("actual value"). On the one hand, this is part of the quality assurance to meet requirements requested by law. On the other hand, this guarantees a final product with most widely standardized functional properties.
Fig. 7.7 Combination of process steps (boxes $=$ unit operations) for the production of various tomato products for a range of applications (technofunctionality)

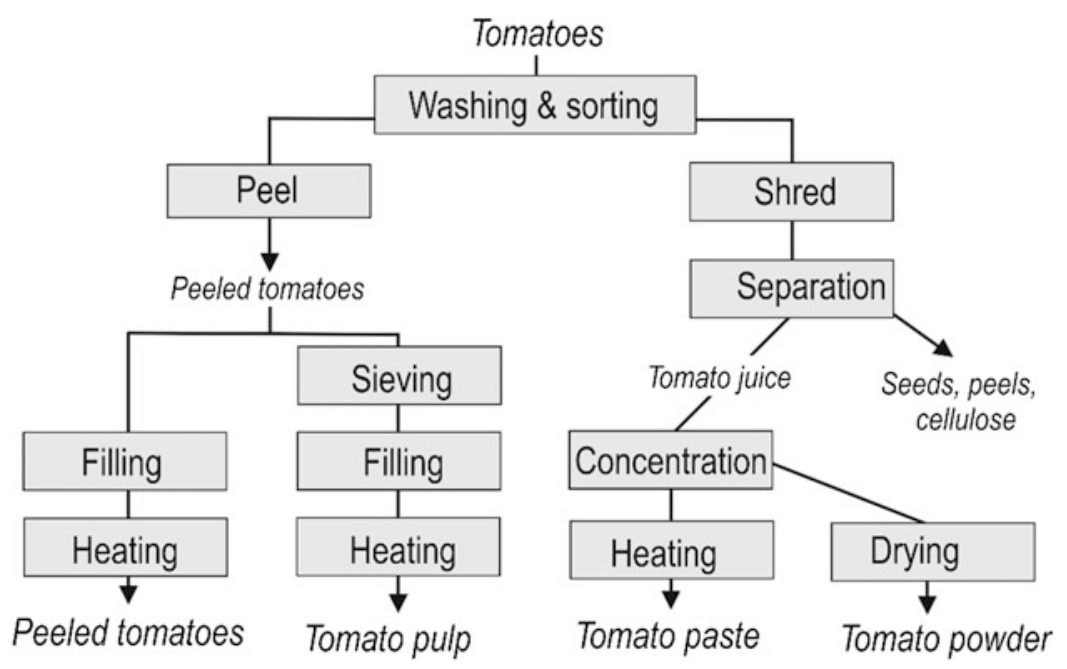


As the sterilization of larger containers $(300-1500 \mathrm{~kg}$ ) is not possible (heating and cooling would take hours and affect the quality of color, texture, taste, etc.), the products are continuously heated in heat exchangers, kept hot for a short, defined period of time, and then rapidly cooled. The products are then filled under aseptic conditions into previously sterilized containers. The production of tomato paste and powder requires further process steps including separation, concentration, and/or drying.

\section{Energy and Water Consumption}

Finally, a note on the energy and water consumption and the utilization/valorization of waste and side streams:

Technical developments not only allow the manufacture of products with a defined functionality and safety, but they also enable economical and responsible exploitation of water and energy resources. For example, the processing of foodstuffs requires an average of only $1-2 \mathrm{~kg}$ of water per $\mathrm{kg}$ of processed product, including the water required for cleaning procedures. In some cases, the water present in the product and removed during concentration is recycled. Energy consumption has also been markedly reduced. Food waste is composted and used either as fertilizer or in biogas plants for heat and electricity generation.

\subsubsection{Strategies/Approaches for New Product Developments}

Innovative companies generally launch a new product idea (Fig. 7.8) following existing trends or resetting trends by responding to changing consumer habits, social conditions (e.g., fullday child care), or trade demands. This also involves innovative technologies, such as membrane separation processes. Once the functional characteristics have been specified and the target consumer groups defined, a marketing concept is required that includes analysis of the market potential with respect to sales volume and price. The functionality of the final product needs to be specified as clearly as possible in order to be able to elaborate a detailed product concept.

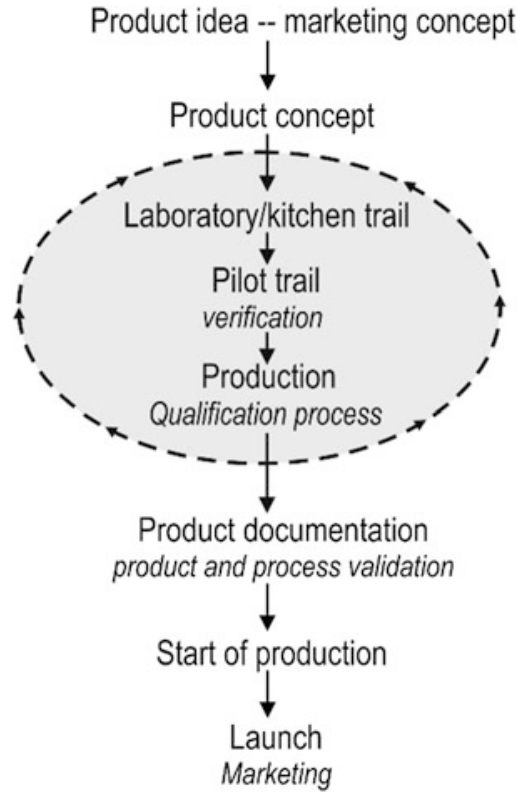

Fig. 7.8 From the idea to the new food product

Numerous aspects have to be taken into account during the product development process. The first step involves (preliminary) experiments in the laboratory, which consider the following aspects: selection of raw materials, additives, and other ingredients, a risk analysis (HACCP), specifications, appropriate test procedures for both the materials and functional properties, suppliers, shelf life, etc. The test procedures for the functional properties need to be defined and validated. The unit operations required to produce a product with certain functionalities as well as their sequence need to be defined. In addition, technical and legal requirements for the facilities have to be considered.

A pilot test then validates the technology used to produce a product with a certain structure and function and experiments are carried out to assess the shelf life. All these steps are repeated several times (Fig. 7.8) before the first production on a scaled-up level starts. At the same time, product declaration and packaging materials have to be adapted to the requirements of the product.

Once all these steps have been completed and the product documentation is available, the official production and supply to retailers can begin. 
Once the new product is established on the market, it is important to constantly improve the recipe and to monitor market success. Only about 1 idea out of 100 will be successful in the long run.

\subsubsection{Concluding Remarks}

The technical processing of food should be seen as a continuous process of development that usually follows consumer demands. New technologies enable, for example, the decaffeination of coffee, the dealcoholization of beer, lactose reduction in dairy products, reduction of allergens, and production of fat-reduced foods that still taste good. Additionally, technical food production allows supply of a wide variety of high-quality food products at reasonable prices. Without technically processed products with a long shelf life, the supply of megacities could no longer be guaranteed, even in developing countries.

A new focus is the valorization of product waste and side streams, biorefinery, and use of "new" resources (depending on the country). Current research studies therefore have a strong focus on, for example, alternative protein resources (e.g., from microalgae and insects) but also on techniques that help to monitor the temperature history of food products during transportation and storage (e.g., time temperature indicators).

\section{Review Questions}

- What are the properties of proteins and fats in food? (use also other sources)

- What is meant by the term $a_{\mathrm{w}}$-value/water activity?

- Describe and explain Fig. 7.6-assess pasteurization and sterilization of milk; consider aspects such as shelf life, storage conditions, nutrient value, and convenience.

- Assess/discuss traditional homemade and large-scale processing regarding present demands of growing cities and world population, food safety, and food security.

- Demonstrate the main steps to bring a new product idea (suggest your own one) to market. Discuss processing requirements needed to produce a certain product and also consider storage temperature as well as shelf life.

\section{Further Reading}

Kessler HG. Food and bio process engineering: dairy technology, 5th edn. Publishing House A. Kessler, Munich

Fellows PJ. Food processing technology principles and practice, 4th edn. Elsevier Science/Woodhead Publishing, Kent

Belitz HD, Grosch W, Schieberle P. Food chemistry, 4th edn. Springer, Berlin

Jay JM, Loessner MJ, Golden DA. Modern food microbiology, 7th edn. Springer, New York 


\subsection{Biotechnological Conversion}

Karin Moß, Marius Henkel, and

Rudolf Hausmann

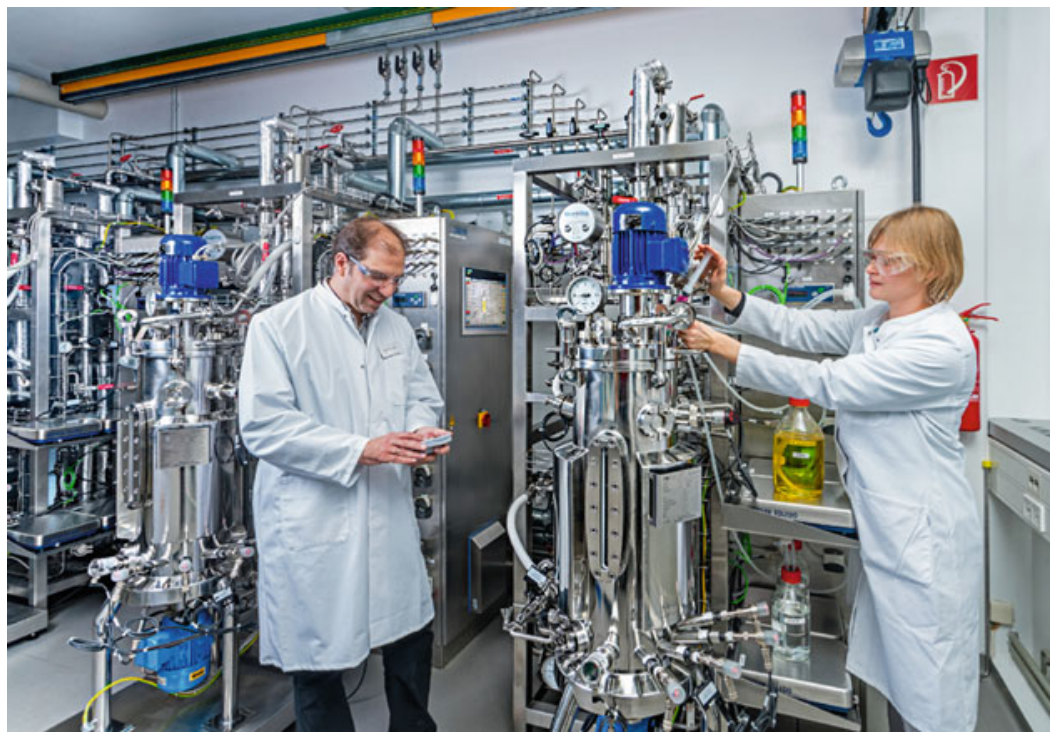

(C) Bildarchiv Uni Hohenheim, photo by Manfred Zentsch

Abstract This chapter presents key terms and concepts in the field of industrial biotechnology. The inclusion of examples, such as ethanol fermentation, and production of polylactic acid (PLA) and propanediol (PDO), allows students to become acquainted with important concepts and their application. Industrial biotechnology, also known as "white biotechnology," is devoted to the exploitation of living cells, such as yeasts, molds, bacteria, and enzymes. In the context of a bioeconomy, it may provide methods to replace and complement petroleum-based synthetics. Industrial biotechnology has been identified as a key enabling technology. Nowadays, industrial biochemicals are mainly produced from carbon sources based on sucrose and glucose. In a future bioeconomy, lignocellulosic plant biomass could become a key feedstock. However, for this purpose, technologies are required that can break down lignocellulosic biomass more easily, with less energy input, and creating less waste than is presently the case. The rapid development of genetic, synthetic biology and bioprocessing methods will lead to biotechnology increasingly complementing chemical industries.

Keywords Industrial biotechnology; Biological system; Bioprocess engineering; Strain development; Biocatalysts; Upstream and downstream processing; Biobased products

\section{Learning Objectives}

After reading this chapter, you should

- Understand the importance of industrial biotechnology for a biobased economy.

- Know the key terms and concepts required to understand basic processes of bioprocess engineering.

- Know biotechnologically derived products of the present and the future. 


\subsubsection{Industrial Biotechnology}

Industrial biotechnology uses microorganisms and enzymes for the production of biobased materials. These materials are utilized in the chemical, food and feed, healthcare, and biofuel sectors. Currently, biotechnology is a niche within the chemical industry, mostly providing products with demanding structure or stereochemistry requirements.

Historically, biotechnology dealt with uncontrolled food processing, such as in the production of wine, beer, vinegar, bread, cheese, and other fermented foods. In 1873, Louis Pasteur received a patent on isolated yeast, and since then the role of yeast in beer brewing and that of bacteria in vinegar fermentation has been exploited, and knowledge-based biotechnology began to evolve.

Contemporary industrial biotechnology, by contrast, uses controlled and induced production of various microbial products. This is achieved through the choice of and, in some cases, the genetic manipulation of the producing organisms and the development of bioprocess engineering. Bioprocess engineering provides both sterile conditions and control of several physiologically important parameters such as temperature $(\mathrm{T}), \mathrm{pH}$, dissolved oxygen $\left(\mathrm{pO}_{2}\right)$, and input of carbon and nitrogen sources as well as other components. Today, such methods enable reproducible processes to be performed, thus ensuring product quality.
There are three phases in bioprocess engineering: upstream processing, bioreaction, and downstream processing (Fig. 7.9). Upstream processing refers to all operations for the planning and preparation of the bioreaction. This includes the choice of the suitable biological system, the appropriate physiological parameters, as well as the strain development. The practical preparation of the bioreaction-i.e., preparation of media, sterilization of bioreactor, and preparation of pre-cultures-also belongs to this step. During the bioreaction, a given substrate is converted into the desired product by a biological system. Microorganisms (bacteria, yeast, fungi), mammalian cells, and enzymes may be utilized. As the resulting product typically comprises no more than $10-15 \%$ of the fermentation broth, downstream processing is needed in order to separate and purify the desired product.

\subsubsection{Biological System}

Bioprocess engineering employs biocatalysts, microorganisms, and cell lines, or parts thereof, for the generation of value-added products. The huge potential of the multitude of naturally occurring organisms that could be used has not yet been exploited. The phylogenetic tree in Fig. 7.10 shows biotechnologically important groups of organisms found within the prokaryotes (cyanobacteria, proteobacteria,
Fig. 7.9 Schematic overview of upstream, bioreaction, and downstream processing in biotechnology. The choice of the biologic system as well as conditions and culture medium belong to the upstream processing (by Johannes Kügler)

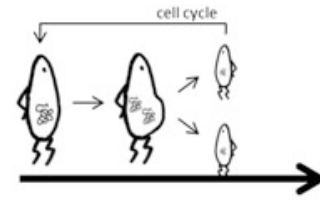

Biological system

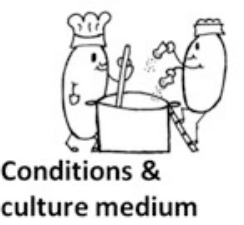

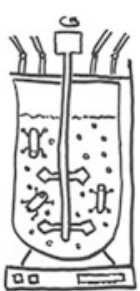

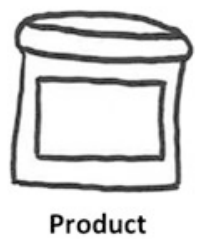

Bioreactor

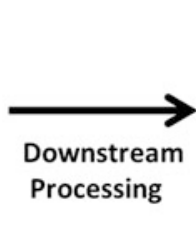

Downstream Processing

Product 


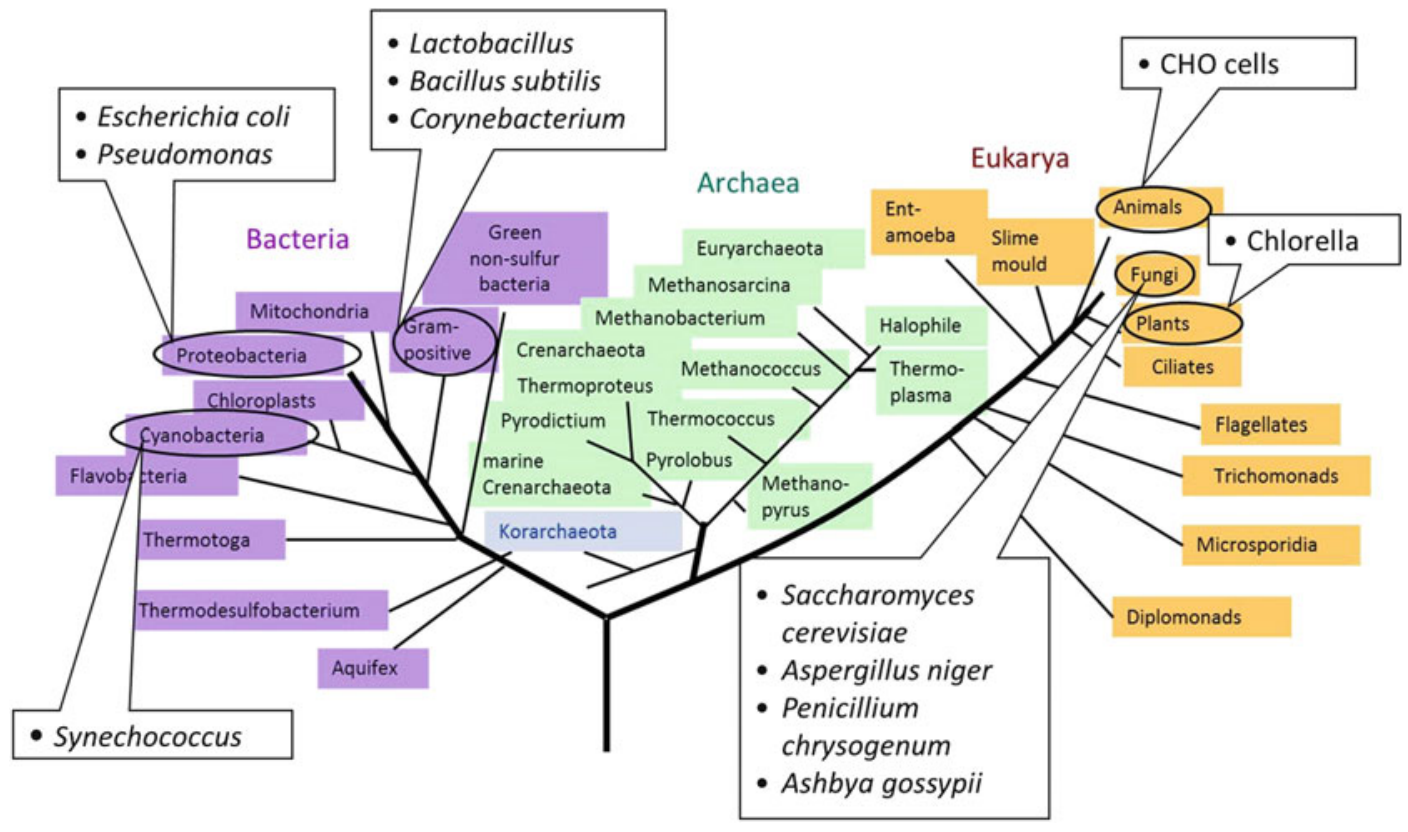

Fig. 7.10 Phylogenetic tree with important biotechnological used microorganisms

Gram-positives) and the eukaryotes (fungi, animals, and plants). For the choice of a suitable biological system, it is important that the organism is able to produce the desired product efficiently. The process conditions, such as temperature, $\mathrm{pH}$, and oxygen content, must be chosen according to the physiological requirements of biological system employed.

\section{Important Groups of Organisms for Biotechnology}

The most important microorganisms for biotechnology are bacteria, yeast, algae, and mammalian cells. Important bacteria used in industrial processes are, for example, Escherichia coli (for various processes, e.g., recombinant proteins), Bacillus sp. (detergent proteases, vitamin B2), Clostridium acetobutylicum (acetone, butanol), and Corynebacterium glutamicum (amino acids). They are easily genetically manipulated; robust against shear stress, pressure, and osmosis; show high productivity, cell densities, and growth rates; and are able to grow in comparatively inexpensive media. One disadvantage is that they are often deficient in secretion of proteins and are not able to perform important posttranslational modifications such as N-glycosylation. The bacteria may become infected by phages, possibly destroying the bacteria culture and resulting in the loss of production.

Industrially employed yeast and fungi include Saccharomyces (beer and wine yeasts, ethanol), Penicillium (many antibiotics, e.g., penicillin), and Aspergillus (some antibiotics, many organic acids, e.g., citric acid). Their advantages are the following: high productivity of homologous proteins, high cell densities, very good secretion, fast growth rates, good $\mathrm{pH}$ tolerance (very important for the production of acids), large cell size (simplifies downstream processing), and no problems with phages. Additionally, yeast and fungi can perform posttranslational modification. However, their glycosylation pattern is neither identical nor similar to that of humans, and this limits their use in pharmaceutical products.

The production of therapeutic glycoproteins for pharmaceutical use is performed by mammalian cell cultures. Various cell lines are employed industrially, the most relevant being Chinese hamster ovary cells $(\mathrm{CHO})$, but also others to a 
lesser extent. Mammalian cell cultures are very sensitive in comparison to bacteria, yeast, and fungi. They grow very slowly, have only low cell densities, are sensitive to shear stress and osmosis, and require high investment and process costs. However, one advantage is that they perform posttranslational modification and glycosylation pattern identical to that of humans. These properties make them the standard solution for therapeutic protein production.

Homologous proteins: Proteins derived from the host strain's DNA.

Heterologous proteins: Proteins derived from the DNA of another organism than the host strain in which it is expressed.

Posttranslational modification: In protein synthesis, DNA sequences are first transcribed into RNA by RNA polymerase and then translated intro proteins by ribosomes. The protein's structure may then be modified, for example by the removal of biochemical groups or the addition of (in-)organic groups.

Glycosylation/glycosylation pattern: This is a specific posttranslational modification of the protein, in which sugar residues are attached to the protein. These sugar residues and their varying patterns are recognized by the immune system. It is thus mandatory that therapeutical proteins have the correct glycosylation and sugar residue pattern.

\section{Strain Development: Genetic Improvement of Production Strains}

Wild-type strains do not normally produce profitable quantities of the desired chemical substance. It may even be that the production strain does not naturally produce the desired substance at all. In order to enable the production or improve the productivity, strains are genetically modified. This is called strain development. Methods used include classic screening and mutagenesis, genetic engineering, metabolic engineering (directed mutagenesis), and synthetic biology.

In classical mutagenesis (example: penicillin), the microorganism known to produce the desired substance is mutagenized by chemicals or UV light, which introduces random changes in the genome. A screening is then carried out to select enhanced producers. Mutagenesis and screening are traditionally repeated iteratively for several generations of microorganisms. This approach is very time consuming. Another drawback is the introduction of several random mutations, which individually or collectively reduce the viability of the organism.

If the desired product is a direct gene product (i.e., a protein), genetic engineering is a suitable choice (example: insulin). Here, the gene encoding for the desired protein is additionally incorporated via a vector or chromosomal integration into the production strain, which then produces it either intra- or extracellularly.

In metabolic engineering, the metabolic pathways of a microorganism are improved by enhancement of desired pathways and deletion or attenuation of those that lead to by-products. Bottlenecks are identified through metabolic flux analysis (metabolomics and transcriptomics) and reduced by genetically enhancing biosynthesis routes. In this way, higher product titers (concentrations) with fewer by-products can be achieved (example: L-lysine and succinic acid).

The currently most modern approach is termed synthetic biology. In this approach, pathways are designed based on formerly gained knowledge (example: propane-1,3-diol, PDO) and the biosynthesis is reconstituted in the most suitable microorganism. Modified biosynthesis genes originating from various donors including plants may be exploited. Existing genome, metabolome, proteome, and transcriptome data can be used in computational modeling for further enhancement. In synthetic biology, these data are used to design nonnatural, novel pathways and circuits in production strains. These strains may than be used for industrial 
application. Databases such as National Center for Biotechnology Information (NCBI), BRaunschweig ENzyme DAtabase (BRENDA), Kyoto Encyclopedia of Genes and Genomes (KEGG), and many others are essential for the design of such microorganisms.

\subsubsection{Basics of Bioprocess Engineering}

Bioprocesses are characterized by the utilization of living cells or enzymes as catalysts, which are therefore termed biocatalysts. The production of the biocatalyst is thus the first step in the conversion of a given substrate to a desired product.

\section{Biomass Growth}

Bacteria and yeast multiply by binary fission. Bacteria grow by cell enlargement and subsequent fission in two identical bacteria cells. Yeasts grow by budding: they divide into a mother and a smaller daughter cell, leaving a scar on the mother cell. The daughter cell grows to the same size as the mother cell. Fungi are multicellular organisms and grow either by apical growth or ramification, where a new cell is

Fig. 7.11 Formal classification of growth phases added to an existing one. The rate of growth in the reactor is called the specific growth rate $(\mu)$. This may vary in a given bioprocess, depending on nutrient availability, substrate inhibition, accumulation of metabolites (acetate, alcohol, lactic acid), and population density. Typically, different growth phases can be distinguished (see Fig. 7.11): Initially microorganisms adapt to the new environment, which is apparent in the so-called lag phase, where the growth rate is zero. This is followed by an acceleration phase with an increased growth rate. A subsequent phase with constant growth rate, the exponential phase, is then observed. Population growth is finally limited by consumption of available nutrients and levels off. In bioreactor cultivations, the rates of growth and product formation are controlled by the setting of process conditions and feeding-in of nutrients.

\section{Media Composition and Culture Conditions}

In bioprocesses, the medium is the liquid in which the bioreaction is performed. It provides the microorganisms with an energy source and all necessary nutrients. Biomass is composed mainly of the elements carbon [C], oxygen [O], nitrogen $[\mathrm{N}]$, hydrogen $[\mathrm{H}]$, potassium $[\mathrm{K}]$,

- Proportional plot

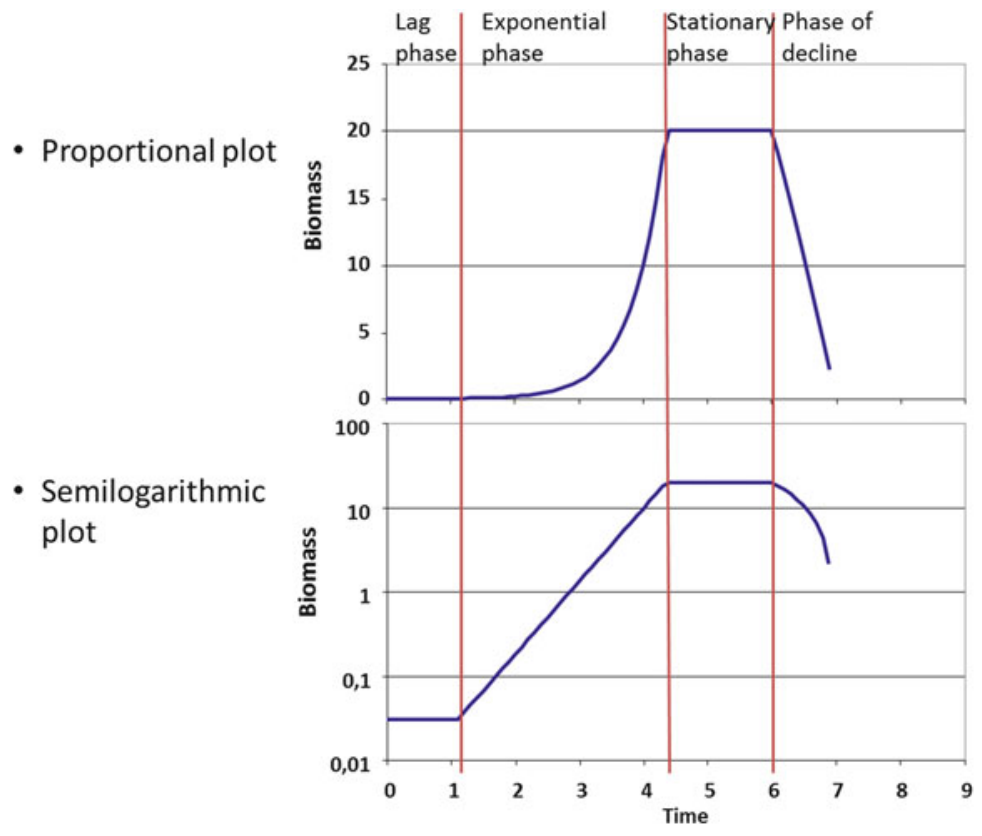

- Semilogarithmic plot 
phosphorus $[\mathrm{P}]$, and sulfur $[\mathrm{S}]$ and other microelements. In order to produce biomass, all these elements have to be present in the medium in a suitable concentration. Additionally, other growth factors such as vitamins and essential amino acids may be required. If any of these are missing or have been consumed, the cell growth will stop. However, as the cells are still alive, they still consume nutrients for cell maintenance. For most biotechnological processes, the carbon and energy source consists of carbohydrates such as glucose, sucrose, or starch, or carbohydrate residues such as molasses. They may also be provided by triglycerides such as vegetable oils. The nitrogen sources most often used are ammonia or ammonium salts, urea, corn steep liquor, yeast extract, soy flour, fish meal, or protein hydrolysates. Media can be differentiated into complex and defined media. Complex media contain at least one non-defined component, e.g., yeast extract or corn steep liquor. In a defined medium, the chemical composition of the carbon source, inorganic salts, as well as any other additions is precisely specified. A defined medium is used when strict control and reproducibility of the process are essential. Complex media are less expensive and can be used when strict control is not necessary.

Bioreactions have to be performed under physiological conditions, i.e., an environment that suits the microorganisms' preferences in terms of temperature, $\mathrm{pH}$ value, oxygen availability, ion concentrations, and water activity.

\section{Bioreactors, Process Kinetics, and Process Control}

Bioreactions are performed in a vessel called a bioreactor, which provides a sterile barrier, thus preventing contamination. A bioreactor can be understood as any defined space or apparatus, in which material conversions take place with the participation of biocatalysts. Functions of bioreactors include mixing (homogenization) of content, suspension of solids (microorganisms, pellets), emulsification of two non-intersoluble liquids, dispersal of gases (air or $\mathrm{O}_{2}$ ) in the liquid, and ensuring that constant physical parameters (temperature, $\mathrm{pH}, \mathrm{pO}_{2}$ ) are in the optimal range. Therefore, devices for tempering, stirring, aeration, $\mathrm{pH}$ control, $\mathrm{pO}_{2}$ control, foam control, and further addition of medium and acid or base are necessary. In this way, the processes can be controlled and reproduced. There are various types and shapes of bioreactors, including bubble column, fluidized bed reactor, tubular reactor (mainly for algae), and stirred-tank reactor. The last is the type most often used (Fig. 7.12).

Bioprocess kinetics describe the timedependent courses of cell growth, product concentration, and substrate concentration during a bioprocess. Important parameters include the specific growth rate $\mu[1 / \mathrm{h}]$, the substrate consumption rate, the product formation rate, the productivity $P_{\mathrm{v}}(\mathrm{g} / \mathrm{L} \mathrm{h})$, and the product yield per substrate $\left[Y_{\mathrm{P} / \mathrm{S}}(\mathrm{g} / \mathrm{g})\right.$ or $\left.\mathrm{Y}_{\mathrm{P} / \mathrm{S}}(\mathrm{mole} / \mathrm{mole})\right]$. If investment and production costs are high, productivity is the most relevant parameter. If substrate costs are high, yield per substrate is most relevant.

Reactions can be performed in batch, fed-batch, or continuous mode. The easiest process mode is a batch culture, where the whole reaction is performed in the initial volume without further nutrient addition over time. The growth rate is not constant, as nutrients are consumed. Nutrients in excess may lead to metabolic overflow reactions. Fed-batch processes are started with a low volume and subsequent addition of nutrients. A constant or an exponential growth rate can be achieved and metabolic overflow prevented. Correspondingly, the volume increases over time. A continuous culture enables a steady flow of fresh medium into and of bioculture out of the reactor. The volume remains constant, but the microorganisms grow at the set growth rate. With this kind of bioprocess, a quasi-steady state of biomass and nutrient concentrations can be achieved. Batch and fed-batch cultivations are advantageous where defined charges are required, e.g., in the pharmaceutical industry. Most industrially relevant bioproduction processes are carried out in fed-batch mode. 
Fig. 7.12 A stirred-tank bioreactor for the controlled growth of microorganisms, with devices for stirring, $\mathrm{O}_{2}$ and $\mathrm{pH}$ control, feeding-in of substrate, base, and antifoam

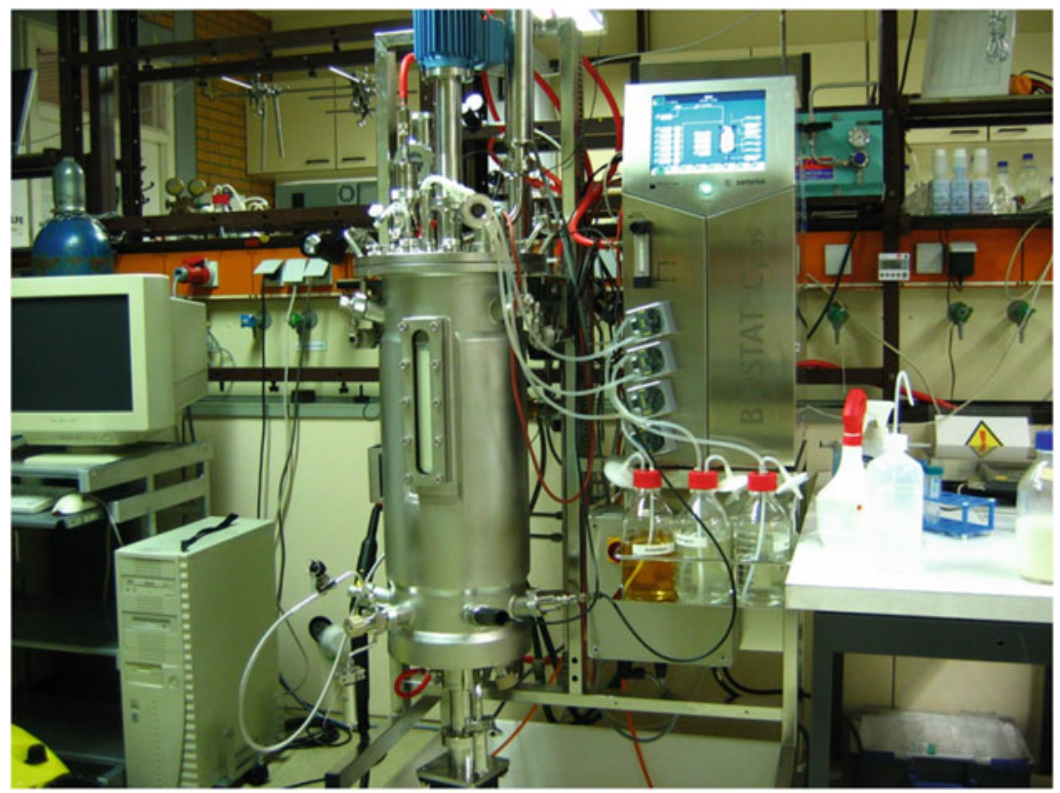

\section{Downstream Processing}

Downstream processing deals with the recovery of the desired product. This is often an extensive task, as the fermentation broth consists of 90-99\% of water and hence the desired product is very diluted. In general, water has to be eliminated during downstream processing. Normally, further by-products are formed, which may be very similar to the target product. If, for example, an intracellularly produced heterologous protein is to be recovered, it has to be separated from numerous other proteins present in the cell, all consisting of chemically similar amino acid chains. For the recovery of the desired product, a generalized purification scheme can be followed, as shown in Fig. 7.13. The first step is nearly always a solid-liquid separation, where the solid biomass is separated from the surrounding liquid. If the target product is an extracellular compound, the biomass is discarded. If the target is an intracellular product, the supernatant is discarded. In the latter case, the cells are then disintegrated, and the solids are once again separated off and disposed of. In

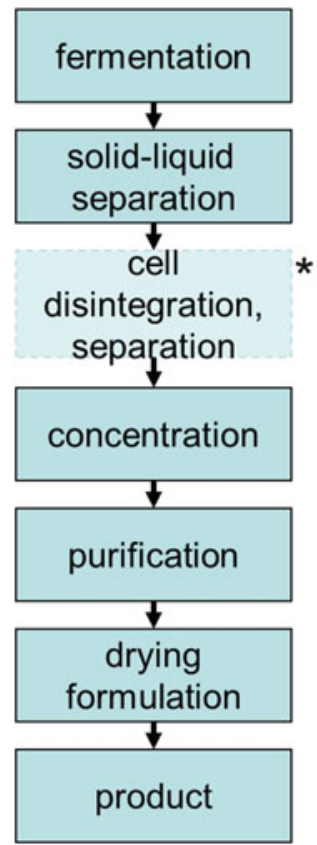

* For intracellular products only

Fig. 7.13 General downstream processing scheme for a biotechnological product 
both cases, the remaining liquid is concentrated and then further purified in the next step. The degree of purification depends on the purity demands of the target product. For medical applications in particular, compliance with legislative regulations is cost intensive. In the last step, the product is dried, formulated, and packed, giving the final product, which is ready to be sold (Fig. 7.13).

\section{Possible Products}

For the biological conversion of renewable materials, microorganisms are used as catalysts. As a rule, only naturally occurring metabolites and products can be produced so far.

These products are formed by metabolization of a given substrate (mostly glucose from starch hydrolysis) to the desired product. In the process, the substrate passes through different metabolic pathways, which can be classified as primary or secondary metabolism. In the primary metabolic pathways, intermediates and products of low molecular weight are formed, which are then either used for the generation of macromolecules or broken down to supply the cell with energy. Examples of primary metabolic pathways are glycolysis and the citric acid cycle. With the exception of fermentation end products, all primary metabolites are normally only synthesized in the amount required by the cell. Overproduction of these products can be achieved by modification of the metabolic regulation. For some primary metabolites, e.g., citric acid, the appropriate choice of fermentation conditions, such as low $\mathrm{pH}$ and excess substrate supply, leads to overproduction. Secondary metabolic pathways generate substances that do not appear to be directly needed for the survival of the organism. Secondary metabolites are often complex in structure and can be biologically active. One example of a secondary metabolism pathway is the mevalonate pathway, which leads to the production of isoprenoids.

Some metabolic pathways require oxygen for the transfer of electrons. In this case, aerobic conditions, i.e., with aeration, need to be provided. Other metabolites are formed in anaerobic conditions, so here no aeration is required.
Not all microorganisms exhibit all kinds of metabolic pathways. There are strictly aerobic, facultative anaerobic, microaerophilic, and strictly anaerobic microorganisms.

Possible products include biomass, as in baker's yeast and starter cultures; primary metabolites such as the end product ethanol and intermediates like organic acids and amino acids; secondary metabolites like antibiotics, alkaloids, toxins, and biosurfactants; specialty products like storage substances, exopolysaccharides (e.g., xanthan), and pigments; enzymes like amylases, proteases, and glucose isomerases; and proteins like recombinant proteins or monoclonal antibodies.

\subsubsection{Application of Industrial Biotechnology}

This section presents bioproducts that have already been established.

\section{Antibiotics}

An antibiotic is a substance, which either inhibits the growth of or kills a bacterium. There are several antibiotics on the market. The best known is penicillin, which inhibits cell membrane formation and thus bacterial growth. Antibiotics have revolutionized the cure of bacterial infections. However, the spread of multiresistance in pathogenic bacteria poses a global health threat, as the infections caused can no longer be treated with widely used antibiotics.

Penicillin was discovered by chance in 1927 by Sir Alexander Fleming. He noticed a fungal contamination growing on a bacterial culture. A halo with no bacterial growth had formed around the fungal (Penicillium notatum) colony. Fleming was able to produce an antibacterial extract with a titer of about $1.8 \mathrm{mg} / \mathrm{L}$ and named it penicillin. At first, penicillin was produced as surface cultures, making upscaling quite difficult. Nevertheless, as penicillin became important, especially for the cure of wounded soldiers, these surface cultures were performed industrially with high labor intensity in up to 100,000 milk bottles in parallel. With the development of 
bioprocess engineering and respective strains, it became possible to produce penicillin in submerged cultures, where the scaling up of the tank is comparatively easy. New and more potent penicillin-producing strains were screened for. With improved strains and bioprocess engineering technology, the penicillin titer was increased by a factor of 40,000 within the following 80 years. Today, about 10,000 different microbial antibiotics are known. However, only a fraction of these is exploited for medical purposes.

\section{Organic Acids}

Organic acids are basic chemicals and serve as building blocks for polymers or as acidifiers. Most of them are produced chemically (e.g., adipic acid), but citric, lactic, gluconic, itaconic, and succinic acid are almost exclusively produced biotechnologically. The four most important organic acids, each with a global production of more than one million tons per year, are acetic acid, acrylic acid, adipic acid, and citric acid. Of these, only citric acid is produced biotechnologically.

\section{Acetic Acid}

About 7,000,000 $\mathrm{t}$ of acetic acid are produced annually by chemical carbonylation of methanol. The conditions applied (150-200 ${ }^{\circ} \mathrm{C}$ and 3-6 $\mathrm{MPa}$ ) are relatively mild for a chemical process. This reaction has a total carbon yield (Yc) of about $95 \%$, i.e., $95 \%$ of the deployed carbon is converted to acetic acid. Biotechnological production by fermentation is modest in comparison: $200,000 \mathrm{t}$ of acetic acid as a component of vinegar. Vinegar is produced by employing bacteria of the genus Acetobacter or Gluconobacter in an incomplete oxidation of ethanol to acetate. This reaction has to be performed under aerobic conditions, as an oxygen molecule is added to the ethanol. The fermentation takes place at $26-28{ }^{\circ} \mathrm{C}$ at normal pressure. Even though the yield $\left(Y_{(\mathrm{P} / \mathrm{S})}\right)$ is $85-90 \%$, the final concentration is only $100-150 \mathrm{~g} / \mathrm{L}$ and the total carbon yield $\left(Y_{\mathrm{c}}\right)$ starting with glucose is about $57 \%$.
Acetic acid is used in the food industry as acidulants, preservatives (E 260), and vinegar. The main fraction of acetic acid is used for the preparation of polymers, such as polyvinyl acetate (PVAC) for paints and varnishes and ethylene vinyl acetate and cellulose acetate for cigarette filters, films, and other plastic products.

\section{Succinic Acid}

Succinic acid is one of the new substances which may pave the way to a biobased industry. It can be used as a platform chemical to be transformed into further products. These may then serve as building blocks, e.g., in polymers. It can also be used directly as a monomer for alkyd and polyester resins; plasticizers; flexibilizers; paint solvents; food additives (E 363); flavor enhancers; potassium, calcium, and magnesium succinate as a substitute for sodium chloride; and acidifier or acidity regulator. Succinic acid is a metabolite within the citric cycle and is gained under anaerobic conditions. Succinic acid can be produced by E. coli (company BioAmber), Basfia succiniciproducens (company Succinity, a joint venture between BASF and Corbion Purac), and $S$. cerevisiae (joint venture between DSM and Roquette). Whereas E. coli and $S$. cerevisiae had to be extensively genetically modified for high-titer succinic acid production, B. succiniciproducens secretes it naturally in relatively high quantities. In $E$. coli and $S$. cerevisiae, the by-product formation is deleted and the biosynthetic pathway enhanced. Under anaerobic conditions, the citric acid cycle is passed through in the reductive direction and succinic acid is formed and secreted into the medium as end product. Technically, this is realized in a two-phased bioprocess. For E. coli and $S$. cerevisiae, biomass is built up in the first phase under aerobic conditions. The second phase is the anaerobic production, where titers of about $100 \mathrm{~g} / \mathrm{L}$ can be achieved.

\section{Biopolymers}

Nowadays, most plastics (300 Mt/a) are of petrochemical origin, and thus rely on a nonrenewable 
resource. The terms "bioplastic" and "biopolymer" incorporate several concepts. One is the biotechnological manufacture of monomers used to produce biobased synthetic materials such as lactic acid, propane-1,3-diol, succinic acid, isoprene, adipic acid, 1,5-diaminopentane, and others. Biobased synthetic materials may or may not be biodegradable. The term "biopolymer" also covers microbial polymers and in general polymers synthesized by living organisms such as polynucleotides (the nucleic acids DNA and RNA), polypeptides (proteins), and polysaccharides (polymeric carbohydrates). Biopolymers utilized as bioplastics are polyhydroxyalkanoates (PHA) such as polyhydroxybutyrate (PHB). However, the term "bioplastic" can also refer to a biodegradable plastic of petrochemical or mixed origin. In this chapter, we focus on biobased synthetic materials. From an economic point of view, polylactic acid (PLA) (global production $\sim 370,000 \mathrm{t} / \mathrm{a}$ in 2011) and xanthan (global production $~ 110,000 \mathrm{t} / \mathrm{a}$ in 2012) are the most important biopolymers.

\section{Bio-Nylon and Diamines, Cadaverine}

Nylon (PA66) was the first 100\% synthetic fiber to be produced. It is a polyamide that can be spun and is produced by the condensation of two chemically produced monomers: 1,6-hexanediamine and adipic acid. Similar biobased, or at least partly biobased, products can be made by replacing the 1,6-hexane diamine by 1,5-diaminopentane and the adipic acid by either sebacic or succinic acid, to give the products PA 5.10 or PA 5.4. These biobased polyamides can, for example, be used in textiles, carpets, and sportswear. 1,5-Diaminopentane (cadaverine) can be produced biotechnologically. For this, the lysine biosynthetic pathway of $C$. glutamicum was extended by one step, the lysine decarboxylase. This product has been manufactured by BASF at pilot scale and processed together with sebacic acid derived from castor oil.

\section{Polylactic Acid}

Polylactic acid (PLA) is a thermoplastic material with a rigidity and clarity similar to polystyrene
(PS) or polyethylene terephthalate (PET). Its availability and attractive structure make it the front runner in the emerging bioplastics market. Its building block is lactic acid, produced by the fermentation of sugars. PLA is biodegradable and hence can be used for packaging material or single-use items, but also for household items. Lactide is formed by intermolecular dehydration of lactic acid. Polylactide (PLA) is prepared by catalytic ring opening polymerization of lactide. Only the pure enantiomers, generally L-lactic acid, can be polymerized. Even though Lactobacilli are wild-type strains able to generate lactic acid, they are no longer used for large-scale lactic acid production. This is due to the product inhibition, $\mathrm{pH}$ sensitivity, and susceptibility to phages. Today, genetically optimized S. saccharomyces strains are used, where an acetate dehydrogenase has been added to the genome. The advantages of this organism are its $\mathrm{pH}$ tolerance $(>\mathrm{pH} 2)$, no problems with phages, and the simple downstream processing. Disadvantages are lower productivities and that ethanol is formed as by-product.

\section{Propane-1,3-Diol (PDO)}

Propane-1,3-diol is a clear, colorless, odorless, biodegradable liquid with low toxicity. It is used in the manufacture of polyesters, for example polytrimethylene terephthalate (PTT) also known as 3GT. From these polyesters, clothing, fibers, automotive parts, carpets, solvents, and coatings are produced. Biotechnological production of PDO was the first industrial application of synthetic biology, as there is no organism known, which produces PDO directly from glucose. But it is known that $S$. cerevisiae converts glucose to glycerol and that the bacterium Klebsiella pneumoniae transforms glycerol to PDO. The cloning of the appropriate genes of both these microorganisms into E. coli gave a recombinant organism able to convert glucose to PDO. This is done in an aerobic process with a final concentration of $135 \mathrm{~g} / \mathrm{L}$ propane-1,3-diol, a volumetric productivity $\left(P_{\mathrm{v}}\right)$ of $3.5 \mathrm{~g} /(\mathrm{L} \mathrm{h})$, and a yield $\left(Y_{\mathrm{P} / \mathrm{S}}\right)$ of $51 \%(\mathrm{~m} / \mathrm{m})$. PDO biotechnologically produced from corn glucose was introduced in 2006 and is considered the first basic chemical 
produced by a strain generated by synthetic biology methods.

\section{Isoprene}

Currently, synthetic rubber (20 million t/a) is derived entirely from petrochemical sources and comprises mainly styrene-butadiene rubbers (SBR). Natural rubbers are isoprene rubber (IR), gained from plants like the rubber tree (Hevea brasiliensis). Isoprene is a colorless liquid which is insoluble in water and volatile, as its boiling temperature is $34{ }^{\circ} \mathrm{C}$. DuPont is working together with Goodyear on the development of a fermentation-based process for the production of bio-isoprene monomer (2-methyl-1,3 butadiene). The largest application area for bio-isoprene is the production of synthetic rubbers for "green" tires and elastomers. Two metabolic pathways exist, which lead to isoprene as secondary metabolite: the mevalonate (MVA) pathway and the methylerythritol-4-phosphate (MEP) pathway. For the fermentative production, an E. coli was chosen as production strain. The MEP pathway is endogenously present in E. coli, and the MVA pathway was additionally cloned into it. Later, an adapted isoprene synthetase was added to the genome. With this strain, an isoprene titer of $60 \mathrm{~g} / \mathrm{L}$ and a volumetric productivity $\left(P_{\mathrm{V}}\right)$ of $2 \mathrm{~g} /(\mathrm{L} h)$ were achieved. The yield $\left(Y_{\mathrm{P} / \mathrm{S}}\right)$ was $11 \%$ isoprene per glucose. This is quite ineffective, given that the theoretical maximum is $24 \%$ for the MVA pathway and $29 \%$ for the MEP pathway. Isoprene is gaseous at $37{ }^{\circ} \mathrm{C}$ and therefore can be continuously removed from the exhaust gas of the bioreactor.

\section{Polyhydroxyalkanoate}

Polyhydroxyalkanoates (PHA) are microbial polymers (polyesters) produced by bacterial fermentation of sugars. Polyhydroxybutyric acid was discovered in 1926 in Bacillus megaterium. Numerous bacteria (>90) including Cupriavidus necator form PHAs as a reserve or storage materials. PHAs are therefore fully biologically degradable and have further useful properties such as thermoplasticity, biocompatibility, and nontoxicity. In 1990, the first biodegradable product $\left(\right.$ Biopl $\left.^{\circledR}\right)$ was launched in Germany. However, the plastic recycling system ("Gelber Sack") introduced here a year later inhibited the advance of this bioplastic. Today, PHA products are insignificant. Nevertheless, Metabolix has successfully commercialized PHA biopolymers for a range of applications. PHAs are considered a replacement for petrochemical polymers. Their potential applications include packaging material, hygiene products, and medical industry products.

\section{Biofuels}

Biofuels are renewable fuels derived from biomass through chemical or biochemical reactions. Depending on the feedstock used, three generations of biofuel can be differentiated. "First-generation" biofuels are based on food crops, such as sugarcane and corn, and are thus in direct competition with food. "Second-generation" or "advanced" biofuels are based on nonfood crops and lignocellulose with reduced or no food competition. "Third-generation" biofuels are based on algae, which avoids competition with food and lowers land requirements. The main biofuel used today is ethanol. Other biotechnologically producible biofuels are biobutanol, alkanes, biodiesel, and biogasoline. For biobutanol production, either Clostridium acetobutylicum or metabolically engineered S. cerevisiae can be used. As a proof of principle for microbial alkane production, the metabolic pathways of alkane production from cyanobacteria were functionally expressed in E. coli, which secretes the hydrocarbons. The company LS9 was heading towards commercialization of these microbial fuels, but the production was stopped as it proved uncompetitive with petroleum-based fuels.

\subsubsection{Conclusion and Outlook}

Currently, industrial biotechnology only accounts for a minor proportion of industrial chemical and material production. In comparison to petrochemical industries, biotechnology only holds a representative market share in a few niche areas. Thus, a major turnaround will be required to convert a major part of the current chemical industry towards a biobased one. 
However, the potential exists for novel, environmentally friendly, knowledge-based products and this potential could generate new, highlevel job opportunities for biotechnologists and bioeconomists in the future.

\section{Review Questions}

- Differentiate between "traditional biotechnology" and modern biotechnology by means of an example.
- Various microorganisms are applied in the industrial production of bioproducts. Assess advantages and disadvantages of the most important organisms.

- In few niche areas, biotechnologically derived products hold a representative market share. Compare and contrast an established product with a prospective bioproduct. Consider factors hindering or facilitating the introduction. 


\subsection{Thermochemical Conversion}

Andrea Kruse

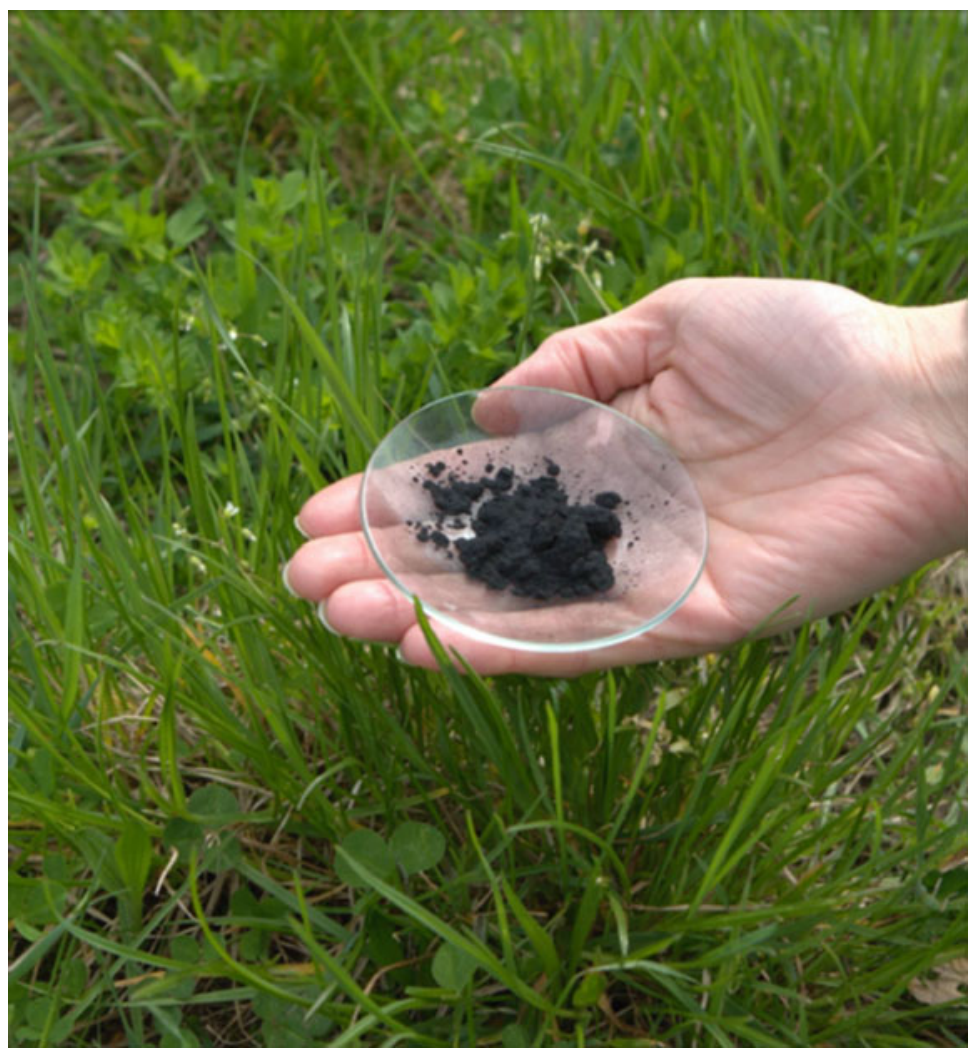

(C) Bildarchiv Uni Hohenheim /FG Konversionstechnologie NaWaRo 440f

Abstract All thermochemical conversions help to overcome two main hurdles in the bioeconomy: the high oxygen content of biomass (low heating value if used as fuel) and the large variability in biomass composition and characteristics. In addition, all thermochemical conversions have in common that they can produce platform chemicals, materials, or fuels from a wide range of biomass types, and that the oxygen content is lower in the product than in the feedstock. The bioeconomy is not only a concept, but also requires technologies that are attractive enough for companies to put into practice, thus creating the technological base for a large-scale use of biomass.

For the substitution of fossil resources by biomass, new technologies are needed. In this chapter, students learn how biomass is converted by (thermo-)chemical conversion technologies to energy carriers or platform chemicals. One example is the conversion of chicory roots to the platform chemical hydroxymethylfurfural (HMF). After further chemical conversion, HMF can be used to produce a wide range of common objects from daily life, including bottles and stockings. Thermal conversion can also be 
applied to produce special carbon materials, e.g., supercapacitors, which will enable a more flexible use of e-cars.

Keywords Pyrolysis; Gasification; Carbonization; Torrefaction; Supercritical water; Hydrothermal processes; Platform chemical

\section{Learning Objectives}

After reading this chapter, you should

- Have an overview of thermochemical conversion technologies.

- Know the range of products which can be produced by thermochemical conversion.

- Be able to choose an appropriate process with respect to (a given) feedstock and desired product.

\subsubsection{Introduction}

When biomass is compared with fossil resources such as coal or oil, the main difference is its higher oxygen content. Cellulose, the main component of biomass, contains one oxygen atom per carbon atom. This reduces the heating value of biomass when used as fuel. The high oxygen content is also a disadvantage when biomass is used as chemical compounds to produce, for example, plastics. Figure 7.14 represents a small part of cellulose, using Lego $^{\circledR}$ bricks to demonstrate its structure. Every red brick (which represents a carbon atom) has an $\mathrm{OH}$ group attached to it. In chemistry, this is called a functional group, which, put simply, means "a place to make chemical bonds." As can be seen, cellulose has a functional group at each carbon atom and is therefore considered "overfunctionalized." For plastics, every basic chemical needs to have two functional groups, one at each end. This enables the formation of long chains, which are the basis of all polymers. In fact, this is what the word polymer means: a long chain of repeating units.

In principle, there are three possibilities to convert biomass into products: (1) biological or biochemical methods applied at low temperatures, (2) chemical conversion at medium temperatures, and (3) thermochemical processes at higher temperatures. This chapter focuses on thermochemical processes, which means chemical conversions that use heat as an important tool for the conversion. Thermochemical conversions are characterized by the desired product and the "agents" added to influence the reaction. The products are solids (char, coke, charcoal), a tarry liquid, and gases. Important agents include oxygen and air. The addition of these leads to a partial combustion of organic material, delivering the heat necessary for the conversion. This is then called an "autothermic process." Another important agent is water, added as a liquid or in the form of steam. Due to the large range of processes which are performed with or without water, the following sections distinguish between dry, steam-assisted, and hydrothermal biomass conversions. All conversion methods have one thing in common: the oxygen content is reduced, as illustrated in Fig. 7.14 for charcoal formation.

The characterization of fuels by the ratio of hydrogen to carbon and the ratio of oxygen to carbon can be displayed in so-called van
Fig. 7.14 Charcoal formation from biomass, illustrated using Lego ${ }^{\circledR}$ bricks. Red bricks represent carbon atoms, blue oxygen atoms, and yellow hydrogen atoms

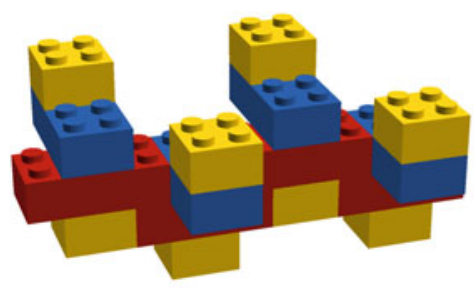

Cellulose

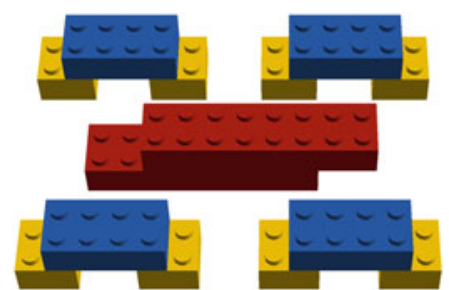

Charcoal and Water 
Fig. 7.15 Van-Krevelen diagram of fossil fuels and biomass

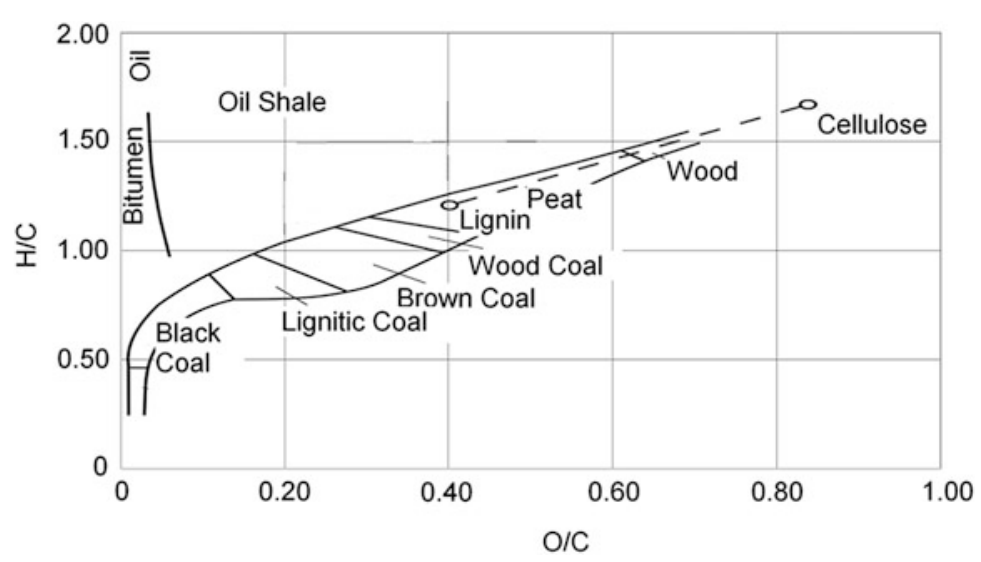

Table 7.3 Overview of dry processes (based on Hornung 2014)

\begin{tabular}{|l|l|l|l|l|} 
& Conditions & $\begin{array}{l}\text { Liquid (tar with water) } \\
(\%)\end{array}$ & $\begin{array}{l}\text { Solid (char) } \\
(\%)\end{array}$ & $\begin{array}{l}\text { Gas } \\
(\%)\end{array}$ \\
\hline Fast pyrolysis & $\sim 500^{\circ} \mathrm{C}$, short hot vapor residence time & 60 & 20 & 20 \\
\hline Slow pyrolysis & $\sim 2 \mathrm{~s}$ & 30 & 50 & 20 \\
\hline Torrefaction & $\sim 500^{\circ} \mathrm{C}, \sim 1 \mathrm{~h}$ & & 77 & 23 \\
\hline $\begin{array}{l}\text { Slow-carbonization } \\
\text { Gasification }\end{array}$ & $\sim 400^{\circ} \mathrm{C}, \sim 10-30 \mathrm{C}, \sim$ hours/days & 30 & 35 & 35 \\
\hline & $\sim 800^{\circ} \mathrm{C}$ & 5 & 10 & 85 \\
\hline
\end{tabular}

Krevelen diagrams. Figure 7.15 shows different types of fossil coal and fossil oil, as well as wood as an example of biomass.

Biomass materials used for thermochemical conversions mainly consist of hemicellulose, cellulose, lignin, and ash. Cellulose and lignin have also been added to the van Krevelen diagram (Fig. 7.15). Lignin has a chemical composition similar to brown coal. As can be seen, fossil coal has both a lower oxygen and hydrogen content in relation to carbon. A line could be drawn from cellulose to coal in Fig. 7.15, corresponding to the elimination of water, as shown in Fig. 7.14. It should be pointed out here that the production of a liquid product similar to fossil oil can only be achieved by the addition of hydrogen, e.g., by coal hydrogenation. A conversion that eliminates oxygen only, instead of water, is not chemically possible. The only possibility of reducing the oxygen content without reducing the hydrogen content is through the elimination of carbon dioxide or carbon monoxide. Here methane or hydrogen is the other end product, not hydrocarbons.

\subsection{2 “Dry" Processes}

Dry processes are considered the more "traditional" conversion processes. In dry processes, the water content of the biomass needs to be below $10 \mathrm{wt} \%$, which means the processes can only be applied to biomass with low water content, such as wood, straw, and crops which produce similar biomass, such as miscanthus. Other biomass feedstocks with higher water content have to be dried before being processed. As this requires a lot of energy, it is not usually done in practice. The dry processes are summarized in Table 7.3 (Fig. 7.16).

Dry biomass conversion generally leads to the formation of a mixture of solid, liquid, and gaseous products, the ratio of which changes with reaction conditions (Table 7.3). At the lowest temperatures of around $300{ }^{\circ} \mathrm{C}$, the so-called torrefaction occurs. For this, continuous reactors like rotating tubes are often used. From a chemical point of view, the heating process first dries the biomass, and then leads to the formation of volatilized compounds from hemicellulose to 

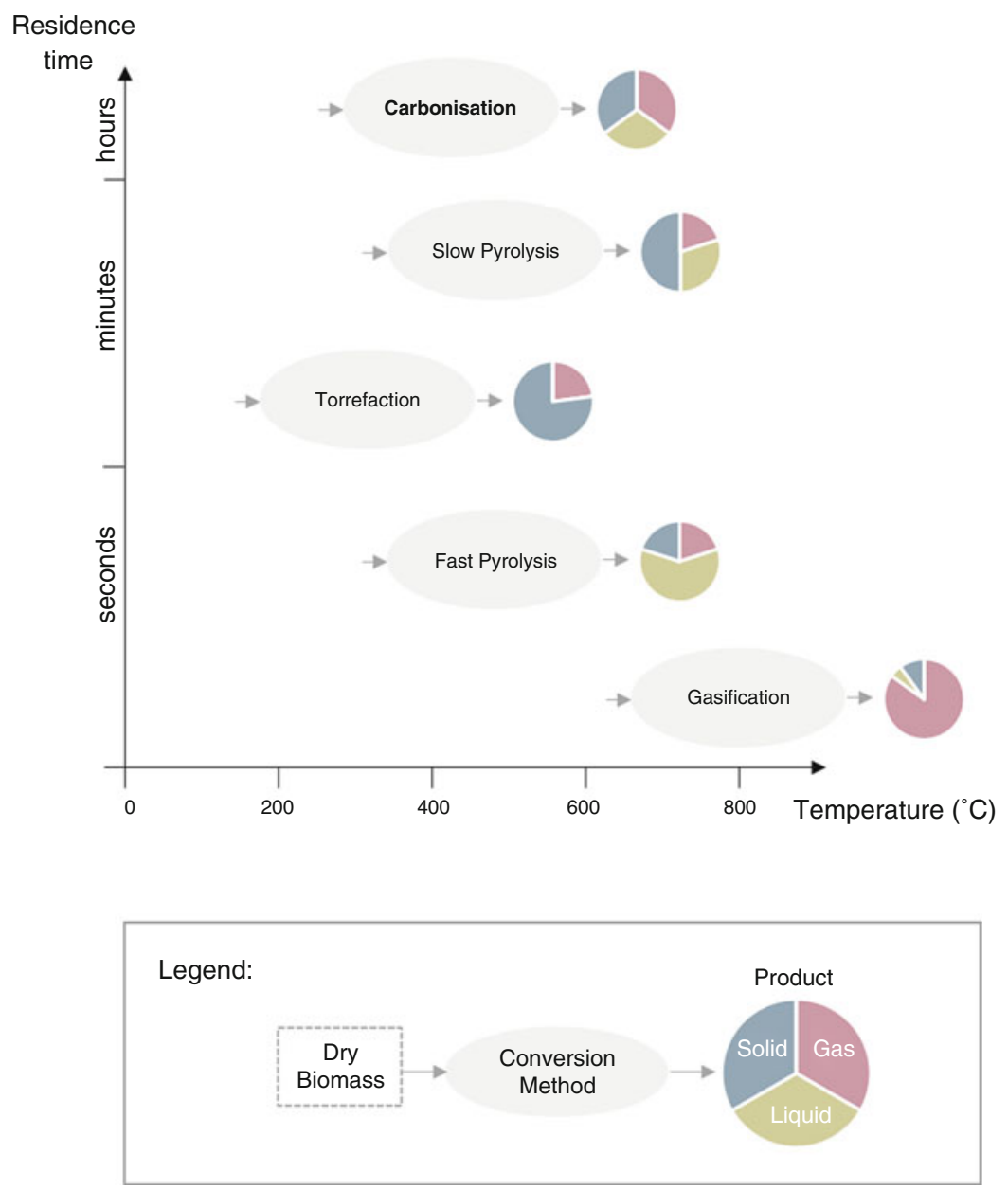

Fig. 7.16 Thermochemical conversion: dry processes

leave a solid, partially charred material. At higher temperatures, cellulose also forms volatiles and starts charring. The condensable gases are combusted outside the torrefaction plant to generate the heat required for the process. Torrefaction is usually regarded as a pretreatment process and is followed by another thermal treatment, e.g., gasification or combustion. The torrefied product has a slightly higher heating value than the original biomass as it has a lower oxygen content [e.g., $19 \mathrm{MJ} / \mathrm{kg}$ to $20-22 \mathrm{MJ} / \mathrm{kg}$ (Gucho et al. 2015)]. This reduces the relative transport costs and, in addition, the structural changes that occur during torrefaction mean that much less energy is required for milling.
Slow pyrolysis is applied to obtain a solid fluid and to reach complete conversion. Here, temperatures of $500-600{ }^{\circ} \mathrm{C}$ and longer reaction times lead to a complete charring of the biomass. Again, a rotating tube is often used and the combustible gases are used for heat generation. The classic process to produce charcoal is with kiln. In these, first a high amount of air is entered so that part of the volatiles formed by wood pyrolysis are burned. Once a high temperature has been reached, the air supply is reduced. Charring then occurs. The process takes several weeks. A large amount of tar compounds and particles leave the kiln with the gases, as no gas cleaning takes place. A more advanced version of the process 
uses a retort. Here, the reaction time is reduced to hours and no oxygen/air is added. The volatiles are combusted outside the retort in a burner and the off-gas is used for heating. There are virtually no emissions of tarry or hazardous compounds (see also "Biokohle-Herstellung, Eigenschaften und Verwendung von Biomassekarbonisaten" in further reading).

\section{Pyrolysis}

Conversion of biomass with heat and no or low amounts of oxygen to avoid combustion.

Many different types of slow pyrolysis reactors have been developed (Demirbas et al. 2016; Kan et al. 2016). Charcoal is used for the production of activated carbon, e.g., as a feed additive, in medicine, as a basis for catalysts, and for gas and water cleaning. It also forms the basis of black powder in fireworks and is used for metallurgic purposes, e.g., the production of copper. Today, the production of advanced carbon materials, such as supercapacitors and electrodes for fuel cells and hydrogen storage as well as modern battery parts, is of particular interest (see also "Advanced Carbon Materials and Technology" in further reading).

\section{Carbonization}

Reaction of biomass leading to a higher carbon content. Charring is a special case of carbonization, usually at around $500{ }^{\circ} \mathrm{C}$ and "dry."

In the case of complete conversion of biomass at around $500 / 600{ }^{\circ} \mathrm{C}$, tar can be regarded as intermediate. The mixture containing hundreds of different compounds reacts further by polymerization processes to form coke and by further splitting to gases. Therefore, if this tar or the so-called pyrolysis oil is the desired product, fast heating up to $500-600{ }^{\circ} \mathrm{C}$, a short reaction time of a few seconds, and quenching for fast cooling down are applied (Table 7.3). This is necessary to avoid the consecutive reactions to coke and gases. The formation of char and gases cannot be avoided completely, but the yields of pyrolysis oil can be maximized by a short and defined reaction time. From the point of heat transfer, fast heating up is only possible by solid-solid contact. There, in all types of reactors applied, biomass is heated up by direct contact with a hot surface, which might be metallic or sand particle. Usually burners, burning the gases coming out of the process, generate the heat necessary. At reaction condition, the pyrolysis oil is a condensate in one, two, or more steps, after separations of the char/coke particles usually by cyclones. If the water content is low, condensation of the pyrolysis oil is possible without phase separation in one step. Pyrolysis oil usually has a water content of $20-30 \%(\mathrm{~g} / \mathrm{g})$ (Bridgwater et al. 1999; Oasmaa et al. 2003). This water is partly a product of the reactions and originates from moisture in the biomass used. This is possible because of a lot of polar compounds like acids, sugars, aldehydes, and ketones are formed. Various types of phenols are also found in pyrolysis oil. If the water content is increased to above $~ 45 \%$, phase separation occurs with the formation of an aqueous and organic phase. In addition, a lignin-like solid is precipitated. Therefore, in the case of relatively high water content it is useful to use a two-step condensation process. Here, an aqueous phase with high contents of acetic acid and an organic phase is produced (Dahmen et al. 2010). Pyrolysis products can be upgraded to car fuels, but this requires large amounts of hydrogen (Wildschut et al. 2009). Pyrolysis oil, or one fraction of it, is used as "liquid smoke" in the food industry and to attract wild pigs for hunting.

In the process called bioliq ${ }^{\circledR}$ (Dahmen et al. 2012), the first step of biomass conversion is fast pyrolysis and the second gasification. This addresses one of the principal challenges of biomass conversion process chains: the widespread, decentralized occurrence of biomass by splitting the biomass conversion into two steps, fast pyrolysis and gasification: The goal of the bioliq ${ }^{\circledR}$ process is to produce a fuel via syngas. To achieve economies of scale, the gasification and synthesis plant needs to have a high throughput, 
which means the biomass has to be supplied from a very large area. However, the amount of energy necessary to transport biomass - a material of relatively low heating value (16-19 MJ/kg, dry matter) - over long distances to supply a large gasification plant is very high. In the bioliq ${ }^{\circledR}$ concept, the biomass is first pyrolyzed in smaller, fast pyrolysis plants. Then the coke and the pyrolysis oil are mixed to a slurry. This slurry has an energy density ten times higher than that of straw, the biomass used as feedstock. The slurry is then transported to the gasification plant. In this case, a gasification temperature above $1000{ }^{\circ} \mathrm{C}$ is used to avoid tar formation.

The products resulting from gasification of biomass, for example in the bioliq ${ }^{\circledR}$ process, are very important in the bioeconomy for the substitution of fossil fuels by biomass. Gasification for the production of syngas and the following use of syngas to produce different products are common processes in industry today. Usually, coal or residues from fossil oil processing are gasified. Therefore, the resource can be changed to biomass to which the available processes for converting syngas can be applied without further need for adaptation. The processes are the production of ammonia, methanol production, Fischer-Tropsch synthesis to produce diesel fuel, oxosynthesis to produce aldehydes, ketones, and others. Besides air or oxygen, water or carbon dioxide is also added as a so-called gasification agent (Hofbauer 2009):

$$
\mathrm{C}_{6} \mathrm{H}_{12} \mathrm{O}_{6}+6 \mathrm{H}_{2} \mathrm{O} \leftrightarrow 6 \mathrm{CO}_{2}+12 \mathrm{H}_{2}
$$

The addition of water increases the yield of hydrogen following Eq. (7.1).

\subsubsection{Steam-Assisted Processes}

In conversion processes that use lower temperatures than gasification, for example pyrolysis, water is added. This alters the gas composition by increasing the hydrogen yield, as shown in Eq. (7.1). In addition, the heat transfer is improved. The heat transfer from gases to solids and throughout the solids is a limiting step for the conversion of biomass in slow pyrolysis and torrefaction. By adding water in the form of steam, a high carbonization conversion of biomass is achieved at lower reaction temperatures compared to the conversion without steam addition (Pütün et al. 2006).

\subsubsection{Hydrothermal and Supercritical Water Processes}

A special case of water being used as an agent in biomass conversion is the reaction in liquid or supercritical water as reaction medium. Biomass conversions in liquid water at increased temperatures are called "hydrothermal." This expression originates from geology where it refers to reactions in liquid water at increased pressure and temperature. Depending on the temperature required, the pressure has to be adapted to avoid evaporation. An overview of hydrothermal processes is given in Fig. 7.17.

In addition to the different conversion processes, Fig. 7.17 includes the vapor pressure curve of water, ending in the critical point. All processes above this vapor curve are conducted in liquid phase. The higher the temperature, the higher the pressure needed to have liquid water as reaction medium. If the critical point is reached, the phase boundary between gaseous and liquid states no longer exists. This is called "supercritical" region.

\section{Supercritical Water \\ Water at a temperature above $374{ }^{\circ} \mathrm{C}$ and a pressure above $22 \mathrm{MPa}$. It has the solvent behavior of a nonpolar solvent like pentane.}

By adapting the pressure, a supercritical medium can be changed from liquid-like to gaseous-like density, without the appearance of a phase boundary. 

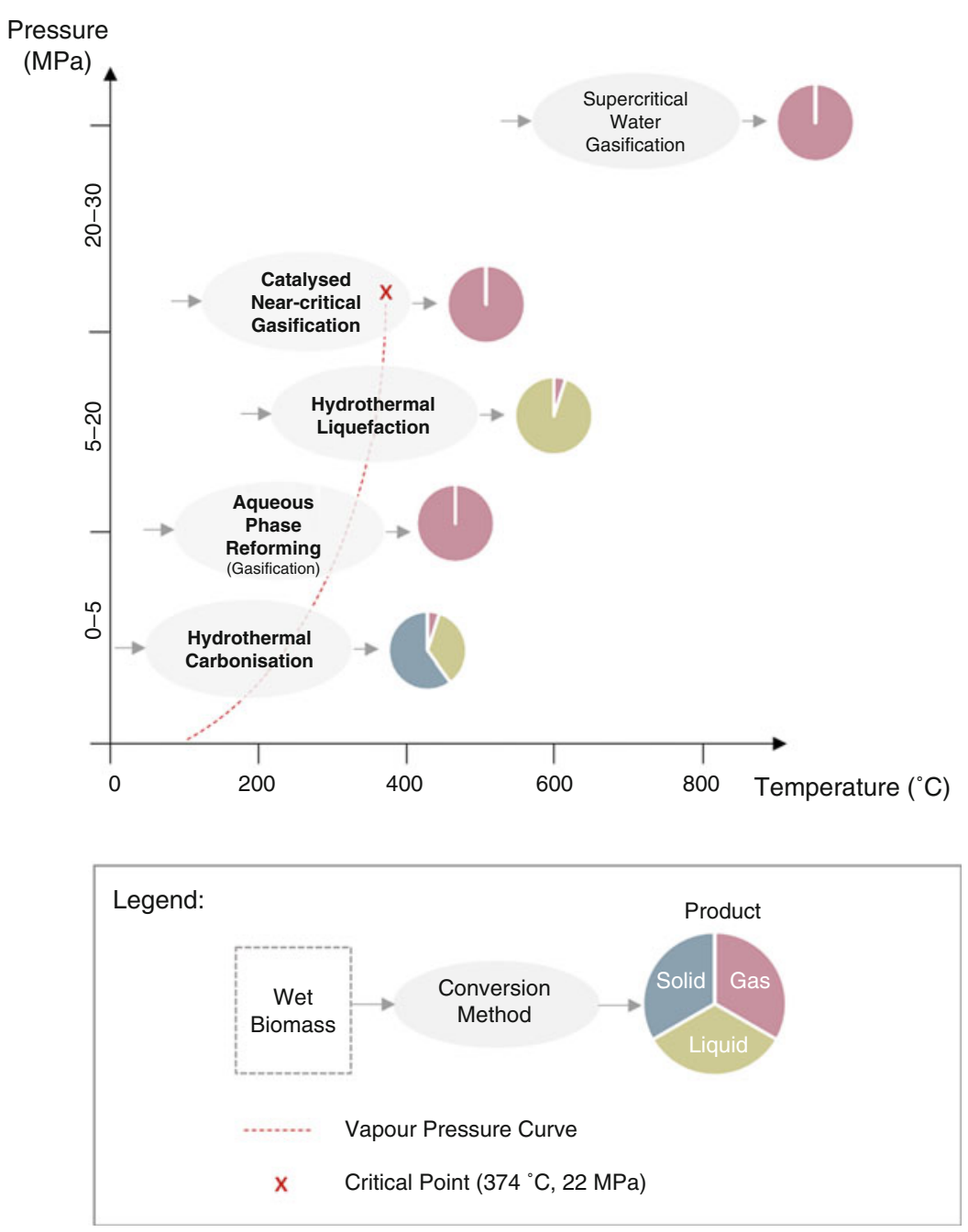

Fig. 7.17 Thermochemical conversion: hydrothermal and supercritical water processes

It may seem surprising that in Fig. 7.17 different processes with fairly similar reaction conditions are next to each other. In addition, the subcritical processes are all in the liquid region. This is due to the special properties of water, which change with temperature. Subcritical water has a higher ionic product, behaving like a mixture of a weak acid and a weak base. Therefore, reactions, which usually require the addition of acid or base, occur without these additions. In supercritical water-in contrast-the ionic product is very low. This means that, per definition, no Brønsted acids (compounds which produce $\mathrm{H}^{+}$ions in water) or bases can exist anymore. On the other hand, the solvent polarity of water decreases with temperature, although water remains as a polar and very reactive molecule. The reason for this is the lower interaction of the water molecules with each other and their faster thermal movement. As a consequence, the solubility of gases and nonpolar compounds increases and the solubility of salts decreases. At around $30 \mathrm{MPa}$, supercritical water behaves like pentane, with complete miscibility with gases, 
very good solubility of nonpolar compounds, and very low solubility of salts (Kruse and Dahmen 2015).

Hydrothermal and supercritical water processes are of special interest for the use and conversion of "wet biomass." A living plant has a water content of 80-90\%. Many biomass residues from agriculture and the food industry also have such high water contents. This kind of biomass can be converted by digestion. In this case, methane is the desired product, but the conversion is not complete because lignin and some type of fibers cannot be digested. The biomass could be dried if other products than methane are desired and a complete conversion is strived for, but this would cost a lot of energy. In hydrothermal processes, wet biomass is converted without drying and the water in the biomass becomes the reaction medium. Therefore, from a chemical point of view, hydrothermal processes are completely different from dry processes. In hydrothermal processes, the polar water molecules split the polar bonds of the biomass by hydrolysis. In contrast to dry processes, which are mainly solid-gas reactions, hydrothermal conversions usually occur in one phase, with fast degradation of the solid biomass by reaction with water. The fast splitting of biomass in water is the reason for the lower temperatures needed at hydrothermal conversions compared to dry processes. On the other hand, the high pressure is often regarded as a disadvantage of hydrothermal conversions of biomass (Kruse and Dinjus 2007).

\section{Hydrothermal}

Reaction conditions in liquid water at temperatures usually above $100{ }^{\circ} \mathrm{C}$ at increased pressure.

Hydrothermal carbonization occurs at temperatures typically in the range of $180-230{ }^{\circ} \mathrm{C}$. Most of the carbohydrates, possibly even the complete biomass, are hydrolyzed and dissolved. The desired product, called HTC-coal or hydrochar, is formed via polymerization (Titirici et al. 2015a, b). This process has been further developed, e.g., to produce supercapacitors to store electricity from renewable resources or in electric cars (Titirici et al. 2015a, b).

\section{Box 7.2 Nutrient Recovery}

In high temperature, dry process nutrients like phosphates are part of a glass-like slag. They are not available for plants, directly. In low-temperature dry conversions, nutrients like phosphate leave the reactor with the char. They have to be leached by strong acids or used together with the char. In hydrothermal conversions, the situation is completely different: Hydrothermal carbonization offers the opportunity to recovery around $80 \%$ as pure fertilizer. In hydrothermal liquefaction, nutrients stay solved in water, and can be used, e.g., for algae growth (López Barreiro et al. 2015a). In supercritical waster salts, also nutrient precipitates and solids can be removed from the reactor.

Hydrothermal liquefaction occurs at around $300{ }^{\circ} \mathrm{C}$ in liquid water, often in the presence of basic catalysts. Here biomass is completely converted to smaller molecules like substituted phenols and different acids or other carbonyl compounds. This process was developed under the trade name "hydrothermal upgrading" by the company Shell (Goudriaan and Peferoen 1990). There are three differences between hydrothermal liquefaction and fast pyrolysis, also producing a liquid or "tarry" mixture from biomass. First, the process temperature of the hydrothermal method is very low. During flash pyrolysis, temperatures of around $500-600{ }^{\circ} \mathrm{C}$ and very short reaction times of a few seconds are applied. The short reaction times are necessary to avoid char/coke formation. Such limitations do not exist for hydrothermal liquefaction; this is the second difference between hydrothermal liquefaction and fast pyrolysis. A wide range of reaction times is applied. In dry flash pyrolysis, large amounts of solid and gaseous products are always formed. The third difference is that hydrothermal liquefaction leads to a low gas yield, mainly 
carbon dioxide and therefore with no energy content, and very low solid yields. The solids formed are often salts. In the reaction conditions, the tarry compounds are dissolved in water. After cooling down, the tarry liquid phase separates from the aqueous phase. Through this separation, the phenols formed from the biomass are concentrated in the tarry phase. Acid and other polar (i.e., oxygen-containing) compounds stay in the aqueous phase. Phase separation may take some time but leads to a tarry product with a high heating value. This heating value is higher than that of the tarry product of fast pyrolysis. In addition, the water content of hydrothermally produced oil is very low $(<0.5 \%(\mathrm{~g} / \mathrm{g}))$ compared to fast pyrolysis oil $(20-30 \%)$. The reason for this is simply that all polar compounds are in the water, not in the oil. A minor disadvantage of the low water content is the rather high viscosity of hydrothermally produced oil (López Barreiro et al. 2014; López Barreiro et al. 2015a). It usually flows above $80^{\circ} \mathrm{C}$. To decrease the viscosity and to obtain a more diesel-like fuel, this oil is hydrogenated. The product is called "HTUDiesel" and in the Netherlands large efforts have been made to establish such a process. Due to the relatively low oxygen content, such a process is energetically and economically more interesting than for pyrolysis oil. Today, hydrothermal liquefaction is often used for the conversion of algae (Valdez et al. 2014; López Barreiro et al. 2015a, b, c). The reasons for this are the following:

1. Algae are very wet biomass and should be converted in water.

2. Fast-growing algae are usually rich in carbohydrates and the lipid content is too low for the production of biodiesel.

3. The aqueous phase contains various nutrients (minerals) which can be recycled (López Barreiro et al. 2015a).

The basic studies on hydrothermal liquefaction were done with wood. Wood is not a typical "wet" biomass. The use of relatively dry wood opens up the opportunity to recycle water, because wood has a relatively low water content.
In the case of wet biomass, the water coming out of the process has to be "treated," maybe by digestion. Hydrothermal liquefaction with a throughput of $100 \mathrm{~kg} / \mathrm{h}$ has been demonstrated in Apeldoorn, the Netherlands (Goudriaan and Peferoen 1990).

A special case of hydrothermal liquefaction is the hydrolysis of lignin to obtain phenols. Here, temperatures of around $400{ }^{\circ} \mathrm{C}$ are usually applied because of the lower reactivity of pure lignin than lignocellulose. In addition, hydrogenation, e.g., by hydrogen and catalyst addition, is conducted. Phenols are interesting platform chemicals for resin production.

Another special case of liquefaction is the production of hydroxymethylfurfural (HMF, Fig. 7.18) from sugars. HMF is one of or perhaps the most interesting platform chemical for the bioeconomy (Teong et al. 2014), mainly because of the two functional groups enabling the formation of many different consecutive products. These chemicals can replace fossil-based plastics, and potential end products include bottles for drinks and nylon stockings. HMF can be produced in hydrothermal conditions (Antal and Mok 1990; Yin et al. 2011) and is assumed to be an intermediate product of hydrothermal carbonization (Kruse et al. 2013).

Depending on the temperature and main product formed, three different hydrothermal gasification processes can be distinguished:

\section{Aqueous phase reforming}

At relatively low temperatures of around $200{ }^{\circ} \mathrm{C}$ and in the presence of a noble metal catalyst, hydrogen is formed from compounds originating from biomass (Davda et al. 2005; Luo et al. 2008). Hydrogen formation as

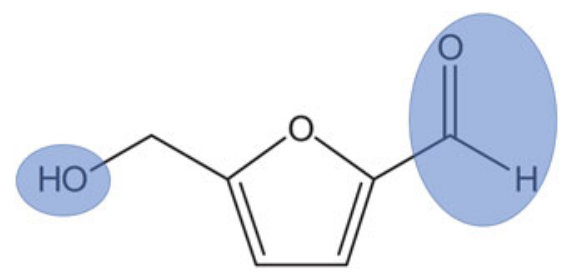

Fig. 7.18 Hydroxymethylfurfural with its two functional groups: an aldehyde and an alcohol 
product is thermodynamically possible at this low temperature, but the concentration has to be very low at around 1\% (Feng et al. 2004; Kruse 2008). A hydrogenation catalyst is necessary. This process can only be applied to biomass compounds, not to raw biomass. Therefore, it can be applied to aqueous effluent of other processes. The most important advantage of this process is that the catalyst uses the formed hydrogen to hydrogenate the feedstock. The extent to which this consecutive reaction occurs depends on which noble metal is used as catalyst (Davda et al. 2005; Huber et al. 2005). In a following step, aromatic compounds which can substitute terephthalic acid can be produced that can be used for PET bottles (Kumula 2011; SerranoRuiz et al. 2011).

\section{Near-critical catalyzed gasification}

Near the critical point, methane is the thermodynamically preferred burnable product. Here, the (nearly) complete gasification and the hydrogenation of carbon monoxide to methane occur in the same reactor. In dry processes, this is not possible, because higher temperatures are needed for gasification, too high for methane formation. The formation of methane from hydrogen requires hydrogenation catalysts $(\mathrm{Ni}, \mathrm{Ru}, \mathrm{Rd}, \mathrm{PT}$, $\mathrm{Pd}$ ) for sufficient yields. Only small amounts of methane can be formed via the decarboxylation of acetic acid, without a catalyst. In principle, two versions of near-critical gasification are conducted: Elliott et al. (2006, 2004) prefer subcritical conditions. The advantage is that salts are still soluble and the risk of plugging is low. In this concept, the biomass is first liquefied and then gasified in a solid-bed reactor filled with the catalyst. A mobile trailer version has also been constructed and is in use (Elliott 2008). F. Vogel and his group prefer supercritical conditions, which have the advantage of good solubility of organic compounds and gases. To handle the salt deposition, a special gravity separator is used (Brandenberger et al. 2013; Dreher et al. 2013). In near- critical catalyzed gasification, the stabilization of the catalyst is a special challenge. In particular, the support of the catalyst has to be stable in the highly aggressive aqueous medium. Pure carbon and $\mathrm{Al}_{2} \mathrm{O}_{3}$ have been found to be sufficiently stable as catalyst support. Elliott et al. (2006) found monoclinic zirconia, rutile titania, and carbon as the best choice for the support. Catalytically active metals are limited to nickel, ruthenium, and rhodium.

\section{Supercritical water gasification}

Biomass with a dry mater content of at least $10 \%(\mathrm{~g} / \mathrm{g})$ and temperatures above $600{ }^{\circ} \mathrm{C}$ is required to produce hydrogen in reasonable concentrations, because of thermodynamic reasons. Challenges are finding suitable reactor materials and a method of handling salt deposition. The reactor material has to be a nickelbased alloy to withstand high temperatures and pressures. However, this material has varying corrosion stability and is usually expensive and difficult to obtain. As mentioned above, the solubility of salts is poor in supercritical conditions (Kruse 2008, 2009), but alkali salts are necessary to catalyze the water-gas shift reaction. Water-gas shift reaction:

$$
\mathrm{CO}+\mathrm{H}_{2} \mathrm{O} \leftrightarrow \mathrm{CO}_{2}+\mathrm{H}_{2}
$$

The equilibrium of the reaction lies to the right of Eq. (7.2), with hydrogen as the preferred product due to the high concentration of water, but alkali salts are necessary to reach the equilibrium. Gasification of glucose without alkali, in particular potassium, salts leads to a syngas with high carbon monoxide content. As biomass naturally contains alkali salts, its conversion usually does not require alkali salts to be added. A catalyst is not necessary, but, e.g., carbon is often used to avoid high temperature requirements or to increase the relative gas yield if the biomass has a high dry matter content.

Supercritical water gasification is a suitable method to convert agricultural residues, process water, sludges, and algae (Kruse 2008, 2009). 
Larger scale gasification plants are operational in Karlsruhe/Germany and Hiroshima/Japan. The German plant converts various types of biomass including corn silage, spent grain, and grass on a scale of $100 \mathrm{~kg} / \mathrm{h}$ slurry (Boukis et al. 2007). In the Japanese plant, the biomass proceeds through a liquefaction reactor before gasification. A special aspect of this plant is that a coal catalyst is fed into the gasification reactor, which can be reused. For details see also Kruse (2008, 2009). Such larger plants are important to assess the performance of the process, for example in terms of energy efficiency.

\section{Review Questions}

- What are the differences between "dry" and "wet" conversion technologies (feedstock, process conditions, and products)?
- What is the role of water in "wet" conversion processes?

- Name products and corresponding reaction conditions of hydrothermal gasification.

\section{Further Reading}

Dufour A. Thermochemical conversion of biomass for the production of energy and chemicals. Wiley, New York. ISBN: 978-1848218239

Hornung A (ed) Transformation of biomass: theory to practice. Wiley, Chichester. ISBN: 978-1119973270

Quicker P, Weber K (eds) Biokohle Herstellung, Eigenschaften und Verwendung von Biomassekarbonisaten. Springer Vieweg, Wiesbaden. ISBN: 978-3658036881

Tiwari A, Shukla SK (eds) Advanced carbon materials and technology. Wiley, Hoboken. ISBN: 978-1118686232 


\subsection{Process and Product Cost Assessment}

Nicolaus Dahmen, Jörg Sauer, and

Simon Wodarz

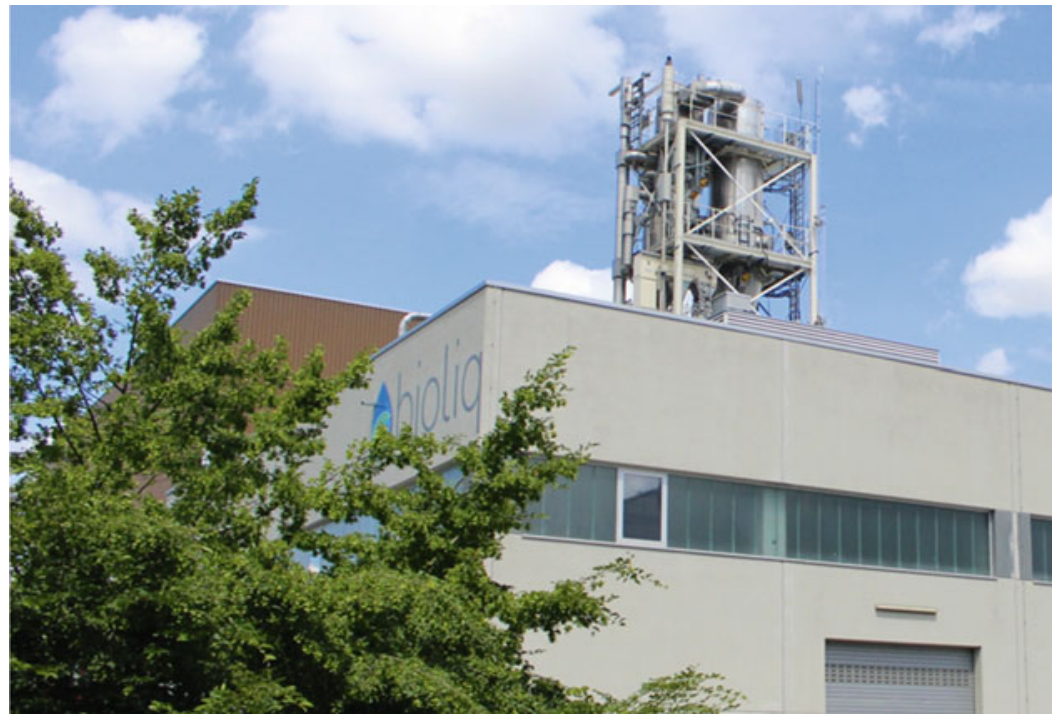

(C) Ricardo Vargas

Abstract When a new product or process is developed and introduced, market analyses and cost estimates are required to examine its marketability and manufacturing or production costs. Before a company takes the decision to construct a production plant and invest in the production and marketing of a certain product, it needs to make sure that the planned process is the most economical and thus the most profitable alternative. In order to make this decision in a sound manner, various tools are used to carry out an economic assessment, weighing up the different costs and revenues against each other. Profitability considerations are also used to develop business plans and assess the state and value of a company. When decisions to invest in chemical conversion plants are taken, a large number of factors have to be taken into account. Hard factors such as profitability and amortization time are important to outline the investment opportunity. However, they are not sufficient to fully characterize the process and thus correctly assess the investment potential. Soft factors also need to be considered in order to weight up further advantages and disadvantages of an investment. These include a number of criteria relating to the technical process, the location of the production plant, and the market situation. Production costs are strongly influenced by the technology applied along with its materials and energy balance. Therefore, process and product cost analysis takes place in early stages and during process engineering. The resulting economic data allow an economic analysis and the creation of a business plan, which help to determine whether a planned project is profitable or not. 
This chapter provides the fundamental knowledge for this process, together with an example of a cost estimation.

Keywords Costing; Investment costs; Manufacturing costs; Variable and fixed costs

\section{Learning Objectives}

After studying this chapter, you should

- Understand the principles of cost estimation in manufacturing.

- Be aware of the most important costdetermining factors.

- Be able to conduct your own simple estimates of process investment and manufacturing costs.

- Be able to understand cost assessments given in the literature.

\subsubsection{Cost Assessment}

In order to make sound investment decisions, the anticipated manufacturing costs of the product to be commercialized need to be known. Since the exact costs cannot be determined in advance, a cost estimate is performed.

The accuracy of a cost estimate increases as the process development progresses. In this period of time, conceptual and design work is carried out prior to building, expanding, or retrofitting a process plant. This includes the determination of all relevant process steps, the type and capacity of equipment, the resources to be used (energy, materials, work, time), and the consideration of all products, desired and undesired. The beginning of the process development is accompanied by a huge uncertaintyup to $\pm 100 \%$ - while an accuracy of $\pm 5 \%$ is not uncommon close to completion of the project. The Association for the Advancement of Cost Engineering International (AACE) proposes a subdivision of cost estimates into five classes (AACE International 2016). These are summarized in Table 7.4 and illustrated graphically in Fig. 7.19. The asymmetric distribution of the uncertainty is particularly apparent.

\subsubsection{Investment Costs}

Investment costs [capital expenditure, total capital cost (TCI)] refer to expenditure that occurs before the plant is commissioned and operated. They consist of plant costs, or ISBL costs (inside battery limits), and off-site costs, or OSBL costs (outside battery limits). In this context, "battery limits" means the geographical location on which the plant is constructed. "Plant costs" refer to expenditure on apparatus, equipment, and other objects and activities directly required for the planning, construction, and operation of a plant, including:

- Main pieces of equipment: reactors, columns, heat exchangers, pumps, etc.

Table 7.4 Accuracy of cost estimates during process development (AACE International 2016)

\begin{tabular}{|c|c|c|c|c|}
\hline Class & $\begin{array}{l}\text { Project } \\
\text { maturity } \\
(\%)\end{array}$ & Description & $\begin{array}{l}\text { Accuracy } \\
\text { lower limit } \\
(\%)\end{array}$ & $\begin{array}{l}\text { Accuracy } \\
\text { upper limit } \\
(\%)\end{array}$ \\
\hline 5 & $0-2$ & $\begin{array}{l}\text { Estimate of order of magnitude, within screening and } \\
\text { feasibility studies }\end{array}$ & $20-50$ & $30-100$ \\
\hline 4 & $1-15$ & $\begin{array}{l}\text { Preliminary estimate, comparison of process alternatives } \\
\text { based on conceptual designs }\end{array}$ & $15-30$ & $20-50$ \\
\hline 3 & $10-40$ & $\begin{array}{l}\text { Definitive estimate, for acquisition of funding and investors, } \\
\text { based on basic engineering }\end{array}$ & $10-20$ & $10-30$ \\
\hline 2 & $30-75$ & $\begin{array}{l}\text { Detailed estimate, basis for contracting and project finance } \\
\text { control }\end{array}$ & $5-15$ & $5-20$ \\
\hline 1 & $65-100$ & $\begin{array}{l}\text { "Check" estimate, after successful negotiation with } \\
\text { contracted companies based on detailed engineering }\end{array}$ & $3-10$ & $3-15 \%$ \\
\hline
\end{tabular}


Fig. 7.19 Schematic diagram showing the asymmetrical limits of cost estimate accuracy above and below baseline at different stages of process development (AACE International 2016)

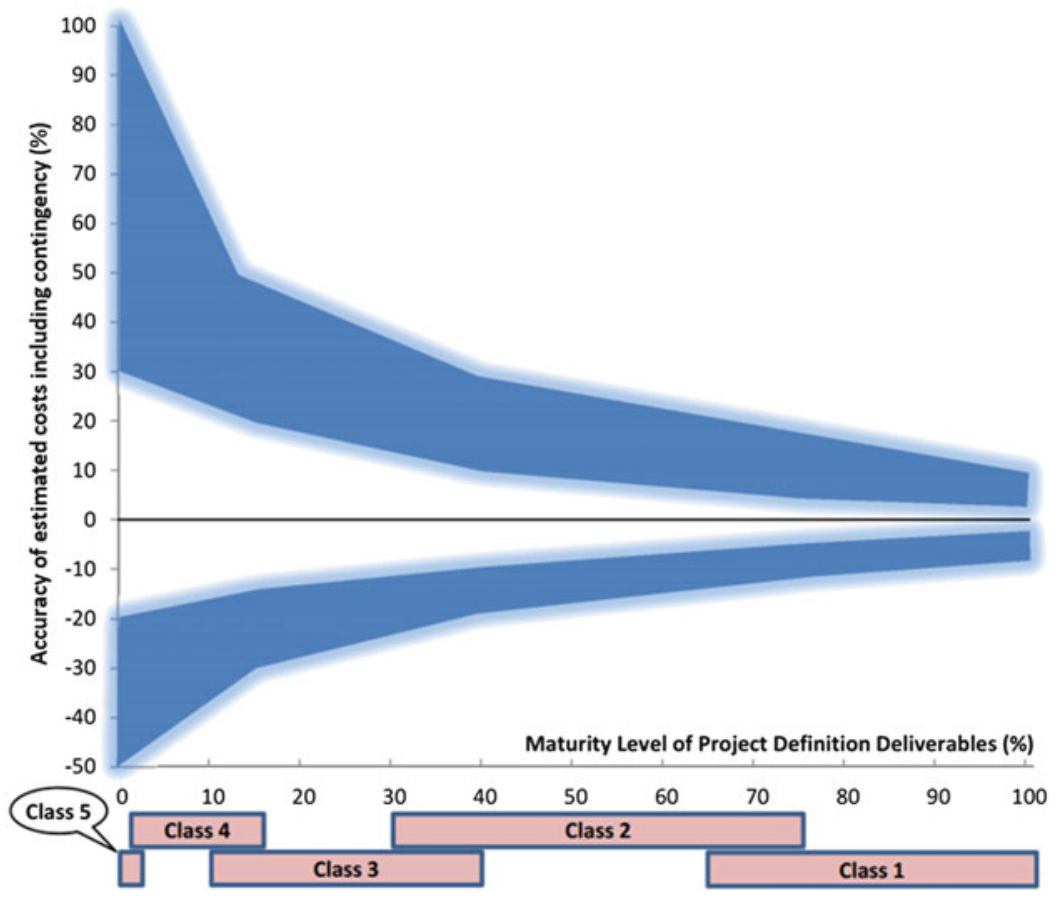

- Pipelines and fittings: tubes, valves, insulation, paint, etc.

- Instrumentation and control: temperature, pressure, and level sensors, flow meters, process visualization software, etc.

- Electrical engineering: power supply, wiring, transducers, switches, etc.

- Construction work: scaffolding, fundament, buildings, etc.

- Plant assembly: staff and sub-contracting

- Miscellaneous: fire protection, interfaces (connection to power and media supply)

- Planning and execution: staff and sub-contracting

- Quality assurance

- Contingencies

"Off-site costs" refer to all costs associated with the plant, but not located inside the battery limits, most commonly items such as utilities or ancillaries.

\section{Inside Battery Limits (ISBL) Costs}

The main pieces of equipment account for a major share of the ISBL costs. For this reason, these are a good starting point for a first, rough estimate of the investment costs, even though, at the end of the day, they do not provide the largest contribution to ISBL costs.

To obtain a first estimate of the key apparatus costs, simple methods such as the capacitance method (Eq. 7.3) are applicable. They can be carried out without specific technological knowledge, purely on the basis of the desired capacity of the new apparatus (or even whole plants) relative to the capacity of comparable, already existing apparatus (or plant):

$$
C_{2}=C_{1}\left(\frac{S_{2}}{S_{1}}\right)^{n}
$$

$C_{2}$ denotes the cost of the new apparatus (or plant) with desired capacity $S_{2}$. $C_{1}$ denotes the already known cost of an existing reference apparatus with a given capacity $S_{1}$. Capacities may be given in mass and volume flows, electrical powers, volumes of reactors, and other vessels or the like. The degression or scale-up factor $n$ indicates how strong the nonlinear relationship between capacity and cost is. Where 
Table 7.5 Example of literature data for estimation of main equipment costs, FOB (Silla 2003)

\begin{tabular}{|c|c|c|c|c|c|}
\hline Equipment & Capacity & $\begin{array}{l}\text { Capacity } \\
\text { units }\end{array}$ & $\begin{array}{l}\text { FOB cost/303 US\$ } \\
(\text { Jan 1990) }\end{array}$ & Correlation range & $\begin{array}{l}\text { Degression } \\
\text { coefficient }\end{array}$ \\
\hline \multicolumn{6}{|l|}{ Agitators } \\
\hline Propeller & 3.0 & $\mathrm{hp}$ & 2.8 & $1.0-7.0$ & 0.5 \\
\hline Impeller & 20.0 & hp & 12.0 & $3.0-100$ & 0.3 \\
\hline Air cooler & 1.0 & $\mathrm{ft}^{2}$ & 0.137 & - & 0.8 \\
\hline Blower, centrifugal & 4000 & $\mathrm{ft}^{3} / \mathrm{min}$ & 60 & $800-1.8 \times 10^{4}$ & 0.6 \\
\hline $\begin{array}{l}\text { Compressor, } \\
\text { centrifugal }\end{array}$ & 600 & hp & 190 & $200-1.8 \times 10^{4}$ & 0.32 \\
\hline \multicolumn{6}{|l|}{ Electric motors } \\
\hline Open drip proof & 60 & $\mathrm{~kW}$ & 3.0 & $0.2-5 \times 10^{3}$ & 1.1 \\
\hline Explosion proof & 100 & $\mathrm{~kW}$ & 9.5 & $0.3-8 \times 10^{3}$ & 1.1 \\
\hline $\begin{array}{l}\text { Evaporator, vertical } \\
\text { tube }\end{array}$ & 1000 & $\mathrm{ft}^{2}$ & 180 & $100-8 \times 10^{3}$ & 0.53 \\
\hline $\begin{array}{l}\text { Heat exchanger, shell } \\
\text { and tube }\end{array}$ & 1000 & $\mathrm{ft}^{2}$ & 14 & $100-5 \times 10^{3}$ & 0.65 \\
\hline Process furnace & 20,000 & $\mathrm{~kW}$ & 750 & $3 \times 10^{3}-1.6 \times 10^{5}$ & 0.85 \\
\hline \multicolumn{6}{|l|}{ Pump, centrifugal } \\
\hline High range & 20 & hp & 9.0 & $2.68-335$ & 0.42 \\
\hline Low range & 0.29 & $\mathrm{hp}$ & 2.3 & $0.1-2$ & 0.29 \\
\hline \multicolumn{6}{|l|}{ Reactors, CSTR } \\
\hline Jacketed & 600 & gal & 17 & $30-6 \times 10^{3}$ & 0.57 \\
\hline Glass lined & 400 & gal & 33 & $30-4 \times 10^{3}$ & 0.54 \\
\hline Rotary vacuum filter & 30 & $\mathrm{ft}^{2}$ & 60 & $4-600$ & 0.67 \\
\hline \multicolumn{6}{|l|}{ Tanks, cone roof } \\
\hline Low range & $12 \times 105$ & gal & 170 & $2 \times 10^{5}-1.2 \times 10^{6}$ & 0.32 \\
\hline High range & $12 \times 106$ & gal & 170 & $1.2 \times 10^{6}-1.1 \times 10^{7}$ & 0.32 \\
\hline
\end{tabular}

$0 \leq n \leq 1$, a larger apparatus (plant) is, in relation, less expensive than a small device. Long-term experience has shown $n$ to be 0.7 for petrochemical plants, between 0.4 and 0.5 for pharmaceutical and specialty chemicals, and between 0.8 and 0.9 for plants with a high consumption of mechanical work by, for example, compressors.

Apparatus costs, as purchased from the equipment suppliers, are called free-on-board $(F O B)$. They are generally estimated via the capacity method (Eq. 7.3). Reference size and price are usually provided by the supplier. The degression coefficients for the main apparatuses can vary significantly (Seifert et al. 2012). Table 7.5 shows data, as typically found in the literature, compiled from Silla (2003), including the capacity of the reference device (always check the units given!), the FOB purchase costs, the correlation range for which the capacity rule is valid, and the degression coefficient.

However, in addition to the purchasing costs of an apparatus, further cost contributions are generated by its installation and integration into the plant. To estimate the total ISBL costs of the planned plant, a structural method such as the Lang method is used to determine these costs of connecting pipes, fittings, measuring and control devices, assembly, and the like. This method, which was developed by Lang in 1940 (Hirschberg 1999), can only be applied once the required main apparatuses have been determined and dimensioned and their prices are known. Instead of listing the individual prices of all other components (i.e., for each valve, tube) their costs are related to the main pieces of equipment based on empirical values; for example the cost of pipes lies between 30 and $100 \%$ of 
Table 7.6 Lang factors for the calculation of ISBL costs

\begin{tabular}{l|l|l|}
\hline Cost type & Structural unit & Factor \\
\hline $\begin{array}{l}\text { Direct } \\
\text { ISBL } \\
\text { costs }\end{array}$ & Main apparatus (FOB) & 1.00 \\
& Tubing and fittings & $0.40-1.00$ \\
& Instrumentation and control & $0.20-1.20$ \\
& Electronics & $0.20-0.50$ \\
& Construction (buildings) & $0.30-1.00$ \\
& Plant assembly, installation & $0.10-0.25$ \\
\hline $\begin{array}{l}\text { Indirect } \\
\text { costs }\end{array}$ & Miscellaneous (insulation, etc.) & $0.10-0.25$ \\
& Engineering & $0.35-0.50$ \\
& Contingencies & $0.15-0.30$ \\
& LF sum factor & $2.70-6.00$
\end{tabular}

the main apparatus costs. These empirical values are included in the calculation of the ISBL costs in the form of so-called Lang factors. These factors, which may be different for different types of plant, are added up and then multiplied by the sum of the costs of the main apparatus to give an estimate of total ISBL costs (Eq. 7.4):

$$
\mathrm{ISBL}=\mathrm{LF} \cdot \sum_{k=1}^{N} \mathrm{FOB}_{k}
$$

The sum of the Lang factors (LF) usually ranges between 2.7 and 6.0. A typical value for chemical plants is, for example, 4.57. A list of the individual factors can be found in Table 7.6. In most cases, additional cost factors need to be taken into account. The tabulated prices often have to be adapted to the following factors:

- Specific technical requirements: corrosion resistance, high pressure and temperature, material compatibility. These need to be considered by separate material factors for each piece of equipment.

- Local factors: local infrastructure, availability and costs of trained staff, transportation costs, transport options.

- International factors: exchange rates, import fees.

- Annual factors: inflation, leading to price development for apparatuses and other equipment. Can be considered by a price index, e.g., according to Kölbel/Schulze, available from the VCI (Verband der Chemischen Industrie) at www.chemietechnik.de.

\section{Outside Battery Limits (OSBL) Costs}

The off-site costs of a chemical plant depend on the infrastructure available at the location of the planned plant. The OSBL stem from the infrastructure required to provide auxiliary materials (e.g., $\mathrm{N}_{2}, \mathrm{O}_{2}, \mathrm{H}_{2}$ ) and energy (in the form of electricity, steam, or fuels) for the disposal of waste materials as well as for storage and overall on-site logistics. In general, make-or-buy decisions have to be made, meaning that it is necessary to consider whether it is more cost efficient to install the infrastructure on-site (within the battery limits) or to buy-in a service via an over-the-fence contract with external partners (Sinnot et al. 2009).

\section{Example: Purchasing Costs of a Furnace}

A pilot plant is to be constructed for the production of a bioenergy carrier by torrefaction of wood pellets. This would usually be fired by hot combustion gases, but the pilot plant is too small for such a design. Instead, the reactor is to be constructed as an electrically heated furnace with a max. capacity of $5 \mathrm{MW}$. We need to know the purchasing cost in Euro of a furnace with an electrical performance of $40,000 \mathrm{~kW}$ to be installed in Germany in 2016. The FOB reference data of a process furnace with a capacity of $20,000 \mathrm{~kW}$, valid from January 1990, can be taken from Table 7.5. The purchase price is given as 750,000 US dollars and the degression coefficient is 0.85 . First, the capacity method is applied using Eq. (7.5) to obtain the price for an oven of the desired capacity:

$$
\begin{aligned}
C_{\mathrm{USA}, \$, 1990} & =750,000 \$\left(\frac{5000 \mathrm{~kW}}{20,000 \mathrm{~kW}}\right)^{0.85} \\
& =\mathrm{US} \$ 230,840
\end{aligned}
$$

Now the price has to be adjusted to the year 2016 by Eq. (7.6). It is assumed that the price of the furnace is similar to that of crude steel (since it is mostly made of steel). Thus the price 
increase is mainly given by the steel price development factor. Using European steel prices (IndexMundi) for comparison would also be permissible, since it can be assumed that the prices of globally traded steel have developed in nearly the same way around the world:

$$
\begin{aligned}
C_{\mathrm{USA}, \$, 2016} & =C_{\mathrm{USA}, \$, 1990}\left(\frac{C_{\text {Steel }, 2016}}{C_{\text {Steel }, 1990}}\right) \\
& =230,840 \$\left(\frac{54.85 \frac{€}{t}}{14.05 \frac{€}{t}}\right) \\
& =\mathrm{US} \$ 901,180
\end{aligned}
$$

Then Eq. (7.7) is used to factor in the location change in the installation of the furnace with a location factor (taken from Sinnot et al. 2009):

$$
\begin{aligned}
C_{\mathrm{GER}, \$, 2016} & =C_{\mathrm{USA}, \$, 2016}\left(\frac{C_{\mathrm{GER}}}{C_{\mathrm{USA}}}\right) \\
& =5.277 .607,23 \$\left(\frac{1.11}{1.00}\right) \\
& =\mathrm{US} \$ 1,000,310
\end{aligned}
$$

Finally, using Eq. (7.8), the exchange rate is taken into account to give the purchase costs in Euro for the furnace with $5000 \mathrm{~kW}$ purchased in 2016 and installed in Germany:

$C_{\mathrm{GER}, €, 2016}=C_{\mathrm{GER}, \$, 2016} \cdot$ Exchange rate

$$
\begin{aligned}
& =5,858,144.02 \$ \times 0.90 \frac{€}{\$} \\
& =900,280 €
\end{aligned}
$$

This results in a purchase price for the electrically heated torrefaction chamber of around $900,000 €$. The calculation was based on the reference capacity and price taken from literature, and updated by the steel price development (as dominant cost factor) for the actual year of purchase, the change in location of the plant construction, and the US\$/EUR exchange rate.

\subsubsection{Manufacturing Costs}

The manufacturing costs of a product can be divided into variable and fixed costs. For their calculation, it is important that the investment costs and the most important process parameters are already fixed or estimated reasonably accurately. Variable costs of production are all costs that occur during the operation of the plant and are dependent on its utilization. Variable production costs comprise the following:

- Material costs: Feedstocks, input and auxiliary materials (obtained from the mass balance of the process)

- Energy costs: steam, fuels (gas, heating oil), electrical power, cooling water, etc. (obtained from the energy balance of the process)

- Waste management: waste water disposal, off-gas treatment, solid residues, etc.

- Other costs: analytics, packaging, shipping, etc.

The fixed costs of production are all costs incurred during the operation of the plant which are not dependent on the degree of utilization of the plant. Fixed costs are, for example:

- Capital-related costs: depreciation of investment costs (fixed capital cost)

- Staff costs: wages, salaries, shift premiums, insurances, company bonuses

- General costs: transport, security, social services, plant management

- Repairs and maintenance

- Taxes and insurance

The capital fixed costs are calculated from the total investment costs, the depreciation time, and the production capacity:

Capital fix costs

$$
=\frac{\text { ISBL }+ \text { OSBL }}{\text { Depreciation time } \times \text { Product capacity }}
$$


The capital fix costs usually account for the largest proportion of the manufacturing costs. Therefore, they are the most relevant factor in the economic assessment of a production process. Additional costs to be considered for the production and sale of chemical products stem from marketing and selling activities (5-25\% of revenues), research (2-5\% of revenues, in larger companies), and for generalia such as financial, legal, and patent departments (3-5\% of revenues) (Baerns 2013). A number of key performance indicators (KPI) are used to calculate the economic performance and profitability of an investment. The earnings (profit) are calculated from the revenues minus all costs within a certain time period. The profit depends on how much product can be sold to the market at the anticipated price. Thus, the earnings are directly related to the workload of a plant and primarily determined by the fixed (also incurred when the plant is not in operation) and variable costs of production.

\subsubsection{Cost Estimation Example}

Synthesis gas, a mixture of hydrogen and carbon monoxide, can be produced from lignocellulosic biomass, for example, in the bioliq ${ }^{\circledR}$ process at KIT (Dahmen et al. 2016). For this process, biomass is pretreated decentrally (close to the place of production) by fast pyrolysis to produce an energy-dense intermediate, which is collected from a number of these decentral plants to be further processed in industrial scale facilities. There, it is gasified to produce syngas, which, after cleaning, can in turn be used to produce various types of fuels and chemical products. Figure 7.20 shows a block flow diagram of the downstream production of gasoline in a hypothetical process. The mass and energy balance of a process is usually available from process simulation using software tools like ASPEN Plus or CHEMCAD. All the main pieces of equipment form blocks of unit operations (cooling, heating, pumping, filtration,

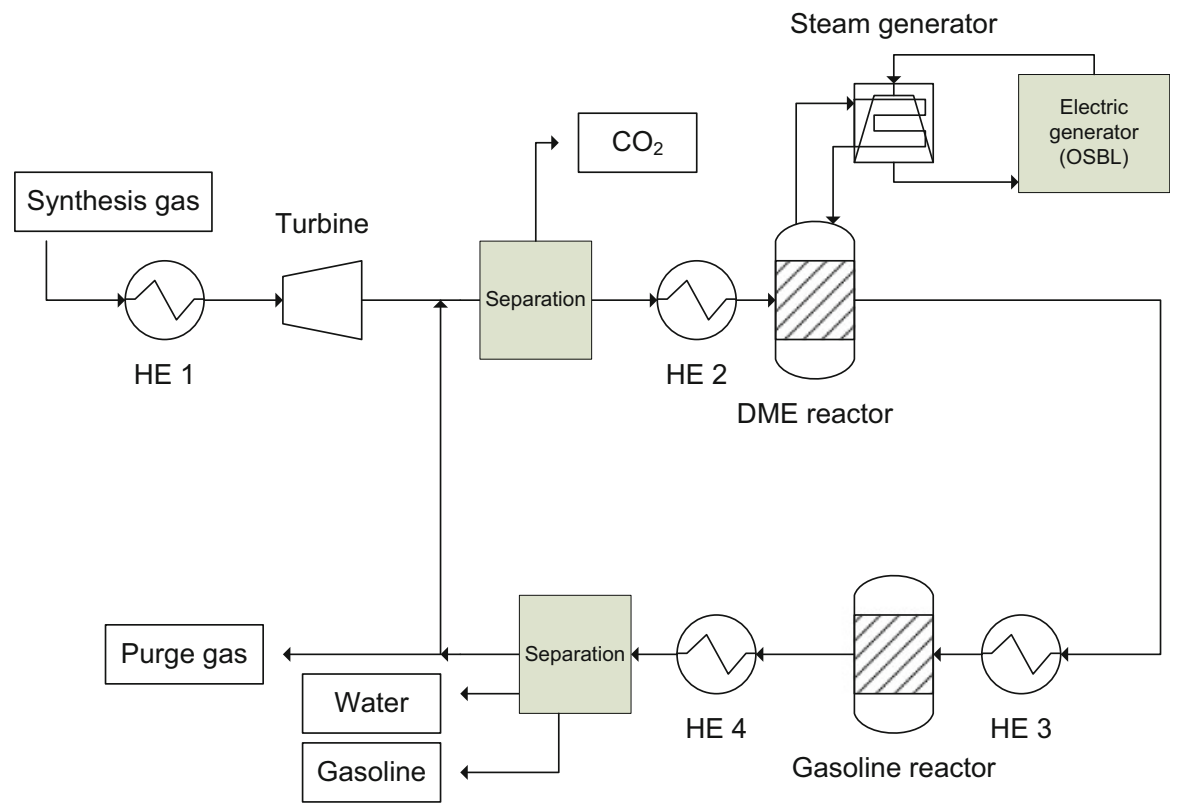

Fig. 7.20 Block flow diagram of gasoline production from synthesis gas 
distillation, reaction, etc.) characterized by specific operating conditions combined with input and output streams of defined composition and conditions. Here, to reduce the complexity, we only consider the synthesis of the raw product for cost estimation. After an initial heat exchange (HE1), the high-pressure syngas (in the bioliq ${ }^{\circledR}$ process, a high-pressure gasifier is utilized) passes through a turbine producing electricity. Then, the $\mathrm{CO}_{2}$ contained in the syngas (formed by partial oxidation in the previous gasification process) is separated at ambient temperature. In heat exchanger HE2, the temperature is adjusted for the first synthesis reactor. Here, the syngas is converted at $200{ }^{\circ} \mathrm{C}$ and $35 \mathrm{MPa}$ into dimethylether (DME) in an exothermic reaction using a mixed catalyst that facilitates methanol synthesis, its dehydration, and the water-gas-shift reaction all at the same time (sum reaction equation: $\left.3 \mathrm{CO}+3 \mathrm{H}_{2} \rightleftarrows \mathrm{CH}_{3} \mathrm{OCH}_{3}\right)$. After reaction, a heat exchanger (HE3) is utilized to adjust the temperature to the optimum for gasoline synthesis over a zeolite catalyst at around $340{ }^{\circ} \mathrm{C}$ (sum reaction equation: $\mathrm{CH}_{3} \mathrm{OCH}_{3} \rightleftarrows-\left(\mathrm{CH}_{2}\right)-+$ $\mathrm{H}_{2} \mathrm{O}$, where $-\left(\mathrm{CH}_{2}\right)$ - stands for a formal hydrocarbon fuel unit in the resulting fuel mixture). The gas is then cooled down by heat exchanger HE4 prior to separation of raw gasoline, water formed during the reaction and non-reacted gas. Half of the remaining gas is recycled to the DME reactor.

A process simulation is carried out with some necessary assumptions to give a material and energy balance: the syngas composition is fixed (30 vol.\% of $\mathrm{H}_{2}$ and $\mathrm{CO}$ each, 20 vol.\% $\mathrm{CO}_{2}, 15$ vol. $\% \mathrm{~N}_{2}$, and 5 vol. $\% \mathrm{H}_{2} \mathrm{O}$ ), and the conversion of syngas to DME is 0.85 and that of DME to gasoline is 1.0. Side products are not considered. $20,000 \mathrm{~kg}$ of gasoline is produced per hour. Process simulation is extremely helpful when heat shifts are necessary: the heat of both exothermic reactions is to be used to preheat colder input streams and to produce steam for use in other parts of the plant. Therefore, efficiencies have to be considered: that of heat exchange is assumed to be 0.8 and that of steam generation 0.5 . From the simulation, the desired capacities of the equipment can be derived for materials $(\mathrm{kmol} / \mathrm{s})$, power (MW), and heat exchangers $\left(\mathrm{m}^{2}\right)$ as given in Table 7.7.

In this example, the specific manufacturing costs are to be estimated for the year 2014 in EUR. It is assumed that the production plant is operated for $7000 \mathrm{~h}$ per year and a depreciation time of 10 years has been accepted.

The specific production costs (in $€ / \mathrm{kg}$ ) are calculated below according to the scheme shown in Fig. 7.21.

In Table 7.7, the main pieces of equipment are compiled together with the reference costs, reference and the desired capacity, and degression coefficients. These allow cost determination of the equipment in the desired size according to the capacity method. For $\mathrm{CO}_{2}$ and product separation, additional costs of $18,750,000 €$ are assumed without further details.

Because reference costs can usually only be found for past years and are typically given in US\$, conversion is required to obtain the actual costs (2014, with price development factor 1.35 ) in the appropriate currency (EUR, at $1 €=$ US\$1.25). Since the date of the reference and currency are not necessarily the same for all pieces of equipment, it is recommended that this procedure is applied for each item. Material factors are also taken into account by using stainless steel instead of carbon steel for most pieces of equipment. The conversion of reference costs given in the literature to reference costs that take price development, exchange rate, and material factors into account is given in Table 7.8.

From these data, FOB costs are calculated according to Eq. (7.3). Then, Lang factors are applied to the FOB total, to give the ISBL costs. By adding OSBL costs, the total capital 
Table 7.7 Calculation of TCI and capital fixed costs using the example of synthetic raw gasoline production from syngas

\begin{tabular}{|c|c|c|c|c|c|c|}
\hline \multicolumn{7}{|l|}{ ISBL calculation } \\
\hline \multicolumn{7}{|l|}{ FOB calculation } \\
\hline & $\begin{array}{l}\text { Reference } \\
\text { capacity }\end{array}$ & $\begin{array}{l}\text { Capacity } \\
\text { unit }\end{array}$ & $\begin{array}{l}\text { Desired } \\
\text { capacity }\end{array}$ & $\begin{array}{l}\text { Reference } \\
\text { costs/EUR }{ }^{\mathrm{a}}\end{array}$ & $\begin{array}{l}\text { Degression } \\
\text { coefficient }\end{array}$ & $\begin{array}{l}\text { FOB costs/ } \\
\text { US\$ }\end{array}$ \\
\hline HE1 & 609 & $\mathrm{~m}^{2}$ & 609 & 224,536 & 0.6 & 224,536 \\
\hline Turbine & 5.3 & MWe & 5.3 & $1,193,186$ & 0.6 & $1,193,186$ \\
\hline HE2 & 571 & $\mathrm{~m}^{2}$ & 571 & 212,062 & 0.6 & 212,062 \\
\hline DME reactor & 1 & $\mathrm{kmol} / \mathrm{s}$ & 2.16 & $4,365,974$ & 0.65 & $7,195,800$ \\
\hline $\mathrm{HE} 3$ & 386 & $\mathrm{~m}^{2}$ & 386 & 177,134 & 0.6 & 177,134 \\
\hline Gasoline reactor & 1 & $\mathrm{kmol} / \mathrm{s}$ & 1.36 & $4,365,974$ & 0.65 & $5,340,334$ \\
\hline Steam generator & 1 & MW & 24.2 & 216,943 & 0.6 & $1,466,279$ \\
\hline HE4 & 384 & $\mathrm{~m}^{2}$ & 384 & 177,134 & 0.6 & 177,134 \\
\hline \multirow[t]{2}{*}{ Separation unit } & & & & & & $18,750,000$ \\
\hline & & & \multicolumn{3}{|c|}{ FOB total/EUR } & $34,736,464$ \\
\hline \multicolumn{7}{|c|}{ Application of Lang factors } \\
\hline Piping and fitting & 0.46 & & & & $15,978,773$ & $15,978,773$ \\
\hline $\begin{array}{l}\text { Instrumentation and } \\
\text { control }\end{array}$ & 0.24 & & & & $8,336,751$ & $8,336,751$ \\
\hline Electronics & 0.2 & & & & $6,947,293$ & $6,947,293$ \\
\hline Construction & 0.7 & & & & $24,315,525$ & $24,315,525$ \\
\hline Plant assembly & 0.28 & & & & $9,726,210$ & $9,726,210$ \\
\hline Engineering & 0.4 & & & & $13,894,585$ & $13,894,585$ \\
\hline \multirow[t]{2}{*}{ Contingencies } & 0.3 & & & & $10,420,939$ & $10,420,939$ \\
\hline & & & \multicolumn{3}{|c|}{ ISBL total/EUR } & $124,356,540$ \\
\hline \multicolumn{7}{|l|}{ OSBL calculation } \\
\hline \multirow[t]{2}{*}{ Power generators } & & & & & & $17,500,000$ \\
\hline & & & \multicolumn{3}{|c|}{ OSBL total/EUR } & $17,500,000$ \\
\hline \multicolumn{7}{|l|}{ TCI calculation } \\
\hline & & & \multicolumn{3}{|c|}{ Total investment cost/EUR } & $141,856,540$ \\
\hline \multicolumn{7}{|c|}{ Fixed capital cost calculation } \\
\hline $\begin{array}{l}\text { Gasoline production } \\
\text { capacity }\end{array}$ & 20,000 & $\mathrm{~kg}$ & & & & \\
\hline \multirow{2}{*}{$\begin{array}{l}\text { Annual operation } \\
\text { time }\end{array}$} & 7000 & $\mathrm{~h}$ & & & & \\
\hline & & & \multicolumn{3}{|c|}{ Fixed capital cost/EUR a ${ }^{-1} \mathrm{~kg}^{-1}$} & 0.101 \\
\hline
\end{tabular}

${ }^{\text {a }}$ Derived from Table 7.8

investment costs, TCI, are obtained. Power generation is assumed to have an efficiency of $100 \%$; losses have already been taken into account in the low steam generation efficiency.

Manufacturing costs are calculated from variable and fixed cost contributions in Table 7.9. Syngas is treated as a buy-in product, which is typical for large plant complexes, where the individual plants are considered as separated business units. Since the heat produced in the highly exothermic reactions is made use of, excess energy can be exported. As such, no energy costs are incurred; in contrast, revenues are gained from power export. Given the high 


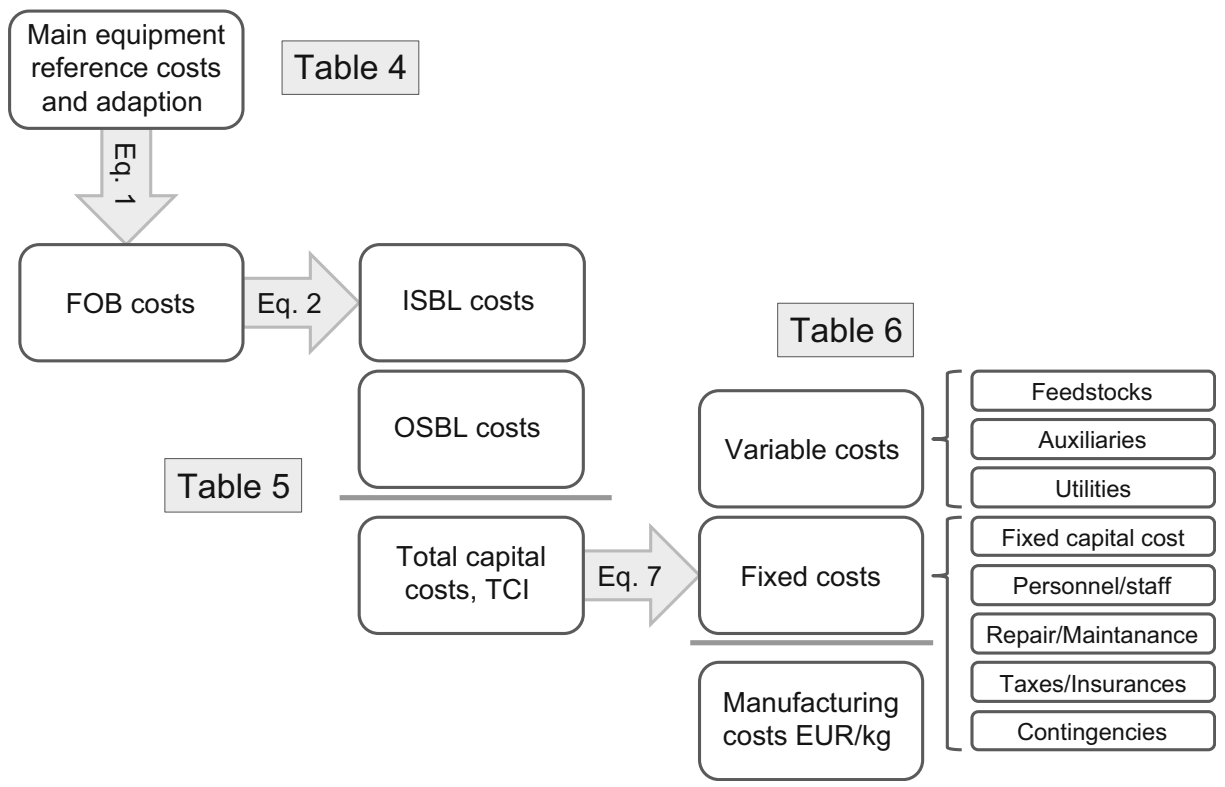

Fig. 7.21 Manufacturing cost calculation scheme

Table 7.8 Reference cost adaption for FOB calculation

\begin{tabular}{|c|c|c|c|c|c|}
\hline & $\begin{array}{l}\text { Reference } \\
\text { costs US\$, } \\
2002\end{array}$ & $\begin{array}{l}\text { Reference costs EUR } \\
2002 \text { (factor } 1 / 1.25 \text { ) }\end{array}$ & $\begin{array}{l}\text { Reference costs EUR } \\
2014 \text { (factor } 1.35 \text { ) }\end{array}$ & $\begin{array}{l}\text { Material } \\
\text { factor }\end{array}$ & $\begin{array}{l}\text { Reference costs EUR, } \\
2014 \text { stainless steel }^{\mathrm{a}}\end{array}$ \\
\hline HE1 & 90,000 & 72,000 & 97,624 & 2.3 & 224,536 \\
\hline Turbine & 550,000 & 440,000 & 596,593 & 2 & $1,193,186$ \\
\hline HE2 & 85,000 & 68,000 & 92,201 & 2.3 & 212,062 \\
\hline $\begin{array}{l}\text { DME } \\
\text { reactor }\end{array}$ & $1,750,000$ & $1,400,000$ & $1,898,250$ & 2.3 & $4,365,974$ \\
\hline HE3 & 71,000 & 56,800 & 77,015 & 2.3 & 177,134 \\
\hline $\begin{array}{l}\text { Gasoline } \\
\text { reactor }\end{array}$ & $1,750,000$ & $1,400,000$ & $1,898,250$ & 2.3 & $4,365,974$ \\
\hline $\begin{array}{l}\text { Steam } \\
\text { generator }\end{array}$ & 200,000 & 160,000 & 216,943 & 1 & 216,943 \\
\hline HE4 & 71,000 & 56,800 & 77,015 & 2.3 & 177,134 \\
\hline
\end{tabular}

Input data for Table 7.7

variable cost contributions of feedstock, those for auxiliaries can be neglected here.

To calculate the fixed costs, the fixed capital costs (as given in Table 7.7), and costs for personnel, repairs, and maintenance, as well as taxes and insurances are considered. The last two are usually expressed as a percentage of the total investment costs. Typical values for chemical plants are given in Table 7.9. Such plants usually require personnel for five shifts as well as a day shift. A typical team would be composed of a plant engineer, some administrative staff, shift 
Table 7.9 Determination of manufacturing costs

\begin{tabular}{ll|l|l|}
\hline $\begin{array}{l}\text { Manufacturing costs } \\
\text { Variable costs }\end{array}$ & & $€ / \mathrm{kg}$ & $€ / \mathrm{a}$ \\
\hline $\begin{array}{l}\text { Syngas } \\
\text { Energy (utilities) }\end{array}$ & $0.214 € / \mathrm{kg}$ & 1.905 & $266,704,873$ \\
\hline $\begin{array}{l}\text { Revenues from power generation } \\
\text { Auxiliaries (catalyst/water) }\end{array}$ & $0.05 € / \mathrm{kWh}$ & -0.060 & $-8,456,432$ \\
\hline $\begin{array}{l}\text { Fixed costs } \\
\text { Fixed capital costs }\end{array}$ & Total variable costs & negligible & negligible \\
\hline $\begin{array}{l}\text { Personnel } \\
\text { Repairs/maintenance }\end{array}$ & & 1.845 & $258,248,441$ \\
\hline \begin{tabular}{l} 
Taxes/insurance \\
\hline
\end{tabular} & $5 \%$ of total capital costs & 0.101 & $14,185,654$ \\
\hline & $1.5 \%$ of total capital costs & 0.004 & 590,000 \\
\hline & Total fixed costs & 0.005 & 709,283 \\
\hline & Total manufacturing costs & 0.002 & 212,785 \\
\hline
\end{tabular}

engineers and operators, and technicians for the repair of mechanical and electrical devices. Here, the equivalent of ten full-time staff is assumed.

\subsubsection{Economic Considerations}

The results of the cost calculation example given above reveal that, in total, $273,946,162 €$ per year or $1.957 € \mathrm{~kg}^{-1}$ need to be earned through the sale of the product to cover the investment costs before any profit can be made from it. There are a number of economic indicators that can give information on the financial state of a company, a process, or project operation These indicators also allow comparison of different process alternatives and sensitivity analyses, e.g., by changing feedstock, energy, selling prices, or other variables with time. Here are some of the most important measures for accounting and finance with practical, somewhat simplified definitions:

Revenue Revenue is the amount of money that a company receives in a certain period of time. In the cost calculation example above, it is money earned by selling the gasoline product, calculated by multiplying the price (which is usually higher than the production costs!) by the amount of product sold in that period of time.

In this context, costs refer to the amount of money or monetary valuation expended in order to produce, market, sell, and deliver the product.

Profit Profit is obtained when the amount of revenue gained from a business activity exceeds the costs, thus: profit $=$ revenues costs. It is worth mentioning that the profit is strongly dependent on the amount of marketed product or its selling price. Therefore, there is always pressure on process optimization to reduce fixed and variable cost contributions.

EBIT Earnings before interest and taxes are a measure of the company's profit that includes all expenses except interest and income tax expenses. This indicator is usually 
applied to whole companies for the purpose of benchmarking and comparison, but can also be applied to individual parts of the business or processes operated.

EBITDA In contrast to EBIT, the earnings before interests, taxes, depreciation, and amortization do not include depreciation and amortization in the calculation. It is closely related to cash flow as one of the most important key performance indicators.

Cash flow The net amount of cash moving into and out of the business in a specified period of time. It is used to assess the quality of a company's income, that is, how liquid it is. It is calculated as the difference between revenues and expenses without considering interest, taxes, and amortization.

Profitability Profitability is a measure of the efficiency of the employed capital investment by relating investment costs to achieved profit. It can be used to compare different business models and process alternatives.

ROCE The return on capital employed relates revenues without interest and taxes (EBIT) to the capital employed. The reciprocal value is the time required to recoup the investments made (payout time).

NPV The net present value is the difference between the present value of cash inflows and present value of cash outflows at a certain time. NPV is used to determine the profitability of a projected investment and includes the consideration of taxes. It is calculated by the following equation:

$$
C(n)=\sum_{t=0}^{n} \frac{c_{t}}{(1+i)^{t}}
$$

where $C(n)$ is the NPV in year $n, c_{t}$ is the cash flow, $i$ is the tax, and $t$ is the number of years.

Figure 7.22a shows the cash flow for a project to produce synthetic gasoline on the basis of the example given in Sect. 7.4.2. In this example, the investment is made to plan, design, and construct the production plant within 3 years. In this period of time, the investment costs expended result in negative cash flows. After this period and following commissioning, the plant produces a fixed amount of product at the same costs and profits $(40,000,000 €$ per year). Figure $7.22 \mathrm{~b}$ shows the NPV curve after interest has been paid. It can be seen that the payout time is achieved after 9 years. This and several other factors are most relevant for decision making in companies and, in particular, profitability of projected investments.

\section{Review Questions}

- Which simple method can be used for a first, rough cost estimate of a plant, when the technology is already state of the art?

- What are the main cost contributions in manufacturing costs?

- Why are capital fixed costs so relevant to manufacturing costs?

- What are the differences between ISBL and OSBL and between variable and fixed costs?

- What are the most relevant economic key indicators? How do they differ from each other? 
a

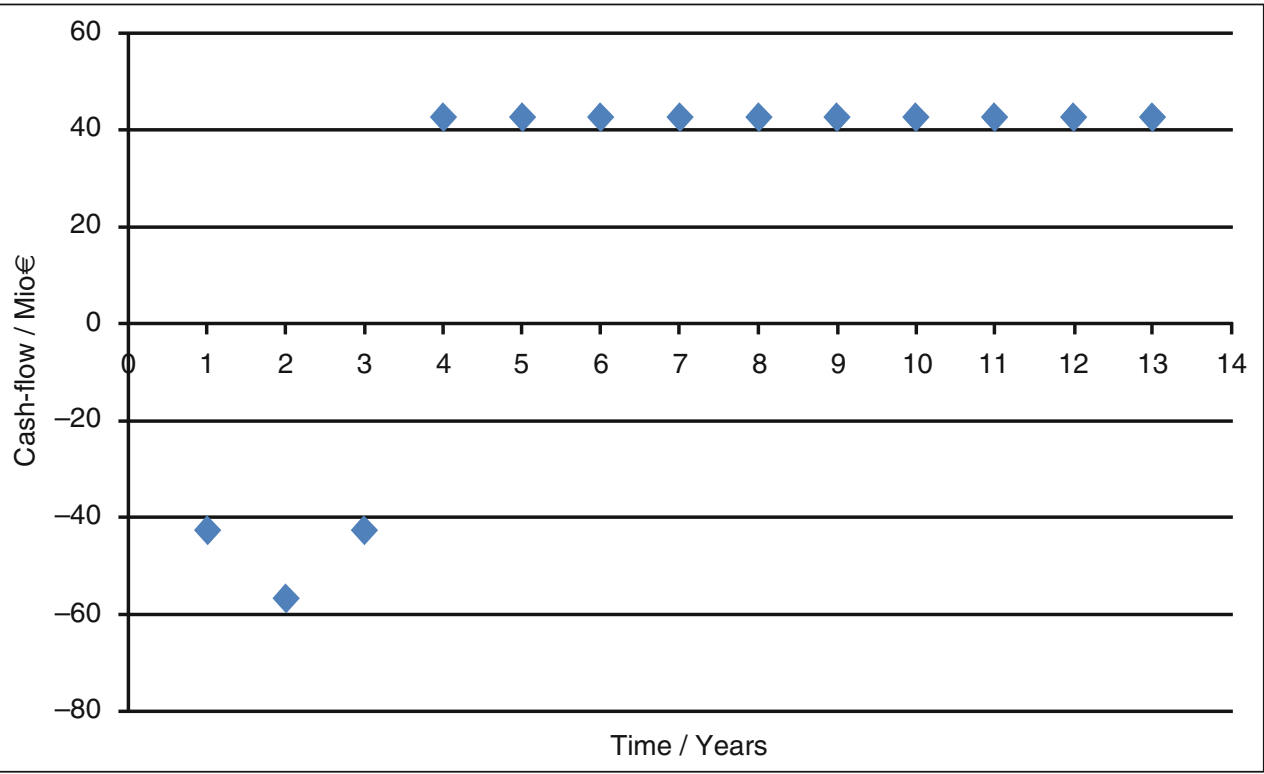

b

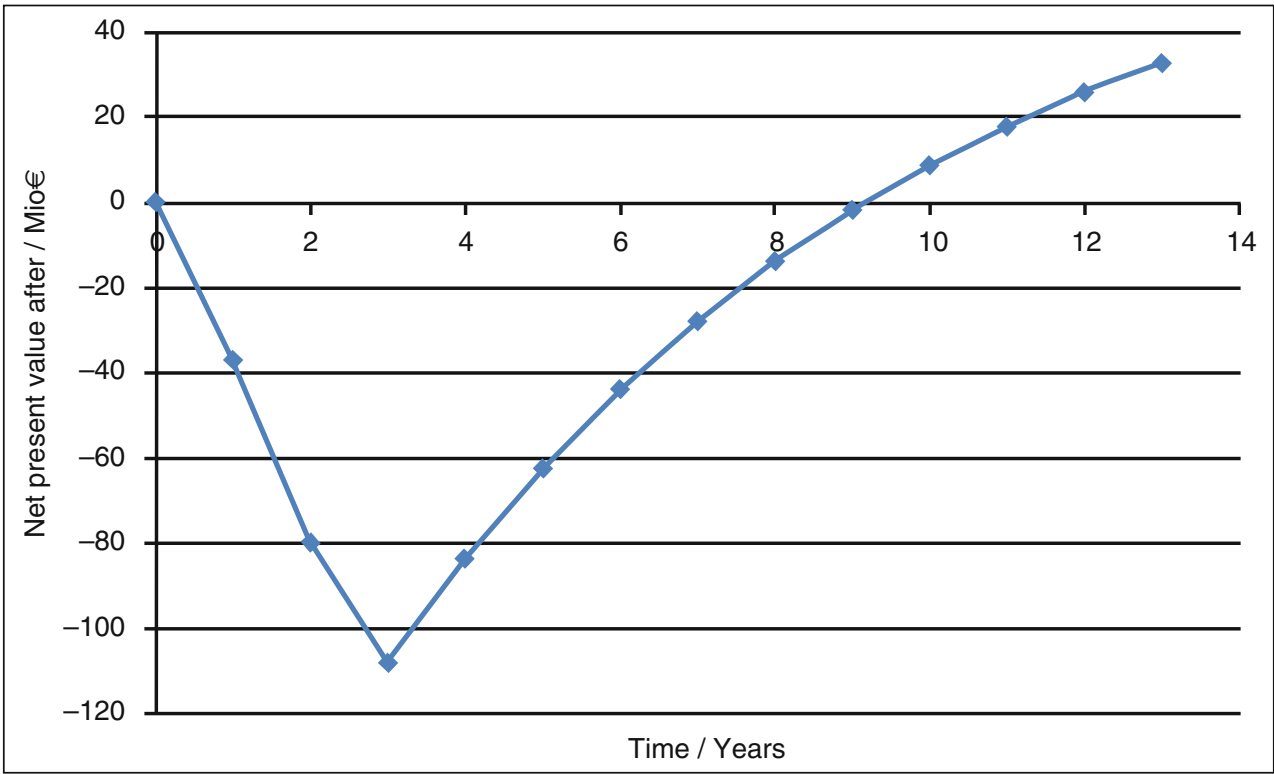

Fig. 7.22 Cash flow and net present value curves for a 3-year investment period

\section{References}

AACE International (2016) Cost estimate classification system. As applied in engineering, procurement, and construction for the process industries (AACE International Recommended Practice No. 18R-97)

Antal MJ Jr, Mok WSL (1990) Mechanism of formation of 5-(hydroxymethyl)-2-furaldehyde from D-fructose and sucrose. Carbohydr Res 199(1):91-109
Baerns M (2013) Technische Chemie, 2 erw Aufl. Wiley, Weinheim

Boukis N, Galla U, Müller H et al (2007) Biomass gasification in supercritical water. Experimental progress achieved with the VERENA pilot plant. In: 15th European conference \& exhibition. Berlin, 7 May 2007

Brandenberger M, Matzenberger J, Vogel F et al (2013) Producing synthetic natural gas from microalgae via supercritical water gasification: a techno-economic 
sensitivity analysis. Biomass Bioenergy 51:26-34. https://doi.org/10.1016/j.biombioe.2012.12.038

Bridgwater A, Czernik S et al (eds) (1999) Fast pyrolysis of biomass: a handbook. CPL Press, Newsbury

Dahmen N, Henrich E, Kruse A et al (2010) Biomass liquefaction and gasification. In: Vertès AA, Qureshi N, Blaschek HP, Yukawa H (eds) Biomass to biofuels: strategies for global industries. Wiley, Chichester, pp 89-122

Dahmen N, Henrich E, Dinjus E et al (2012) The bioliq ${ }^{\circledR}$ bioslurry gasification process for the production of biosynfuels, organic chemicals, and energy. Energy Sustain Soc 2:3. https://doi.org/10.1186/2192-05672-3

Dahmen N, Abeln J, Eberhard M et al (2016) The bioliq process for producing synthetic transportation fuels. WIREs Energy Environ. https://doi.org/10.1002/ wene. 236

Davda RR, Shabaker JW, Huber GW et al (2005) A review of catalytic issues and process conditions for renewable hydrogen and alkanes by aqueous-phase reforming of oxygenated hydrocarbons over supported metal catalysts. Appl Catal B: Environ 56(1-2):171-186

Demirbas A, Ahmad W, Alamoudi R et al (2016) Sustainable charcoal production from biomass. Energy Sources, Part A 38(13):1882-1889

Dreher M, Johnson B, Peterson AA et al (2013) Catalysis in supercritical water: pathway of the methanation reaction and sulfur poisoning over a $\mathrm{Ru} / \mathrm{C}$ catalyst during the reforming of biomolecules. J Catal 301:38-45

Elliott DC (2008) Catalytic hydrothermal gasification of biomass. Biofuels Bioprod Biorefin 2(3):254-265

Elliott DC, Peterson KL, Muzatko DS et al (2004) Effects of trace contaminants on catalytic processing of biomass-derived feedstocks. Appl Biochem Biotechnol 113(16):807-825

Elliott DC, Hart TR, Neuenschwander GG (2006) Chemical processing in high-pressure aqueous environments. 8. Improved catalysts for hydrothermal gasification. Ind Eng Chem Res 45(11): 3776-3781

Feng W, Hedzer J, de Swaan Arons J (2004) Biomass conversions in subcritical and supercritical water: driving force, phase equilibria, and thermodynamic analysis. Chem Eng Process 43(12):1459-1467

Goudriaan F, Peferoen DGR (1990) Liquid fuels from biomass via a hydrothermal process. Chem Eng Sci 45(8):2729-2734

Gucho EM, Shahzad K, Bramer EA et al (2015) Experimental study on dry torrefaction of beech wood and miscanthus. Energies 8(5):3903-3923. https://doi.org/ $10.3390 /$ en 8053903

Hirschberg HG (1999) Handbuch Verfahrenstechnik und Anlagenbau. Chemie, Technik, Wirtschaftlichkeit. Springer, Berlin

Hofbauer H (2009) Gasification-technology overview. In: Bridgwater AV, Hofbauer H, van Loo S (eds) Thermal biomass conversion. CPL Press, Newbury
Hornung A (ed) (2014) Transformation of biomass: theory to practice. Wiley, Chichester

Huber GW, Chheda JN, Barrett CJ et al (2005) Production of liquid alkanes by aqueous-phase processing of biomass-derived carbohydrates. Science 308 (5727):1446-1450

IndexMundi: Eisenerz monatlicher Preis - Dollar pro trockener metrischer Tonne. Online verfügbar unter http://www.indexmundi.com/de/rohstoffpreise/? ware $=$ eisenerz \&monate $=360$. Accessed 29 Jun 2016

Kan T, Strezov V, Evans TJ (2016) Lignocellulosic biomass pyrolysis: a review of product properties and effects of pyrolysis parameters. Renew Sustain Energy Rev 57:126-1140

Kruse A (2008) Supercritical water gasification. Biofuels Bioprod Biorefin 2(5):415-437

Kruse A (2009) Hydrothermal biomass gasification. J Supercrit Fluids 47(3):391-399

Kruse A, Dahmen N (2015) Water - a magic solvent for biomass conversion. J Supercrit Fluids 96:36-45

Kruse A, Dinjus E (2007) Hot compressed water as reaction medium and reactant: properties and synthesis reactions. J Supercrit Fluids 39(3):362-380

Kruse A, Funke A, Titirici MM (2013) Hydrothermal conversion of biomass to fuels and energetic materials. Curr Opin Chem Biol 17(3):515-521

Kumula D (2011) Completing the puzzle: $100 \%$ plantderived PET. Bioplast Mag 6:14-17

López Barreiro D, Samori C, Terranella G et al (2014) Assessing microalgae biorefinery routes for the production of biofuels via hydrothermal liquefaction. Bioresour Technol 174:256-265

López Barreiro D, Bauer M, Hornung U et al (2015a) Cultivation of microalgae with recovered nutrients after hydrothermal liquefaction. Algal Res 9:99-106

López Barreiro D, Beck M, Hornung U et al (2015b) Suitability of hydrothermal liquefaction as a conversion route to produce biofuels from macroalgae. Algal Res 11:234-241

López Barreiro D, Gómez BR, Hornung U et al (2015c) Hydrothermal liquefaction of microalgae in a continuous stirred-tank reactor. Energy Fuels 29(10):64226432

Luo N, Fu X, Cao F et al (2008) Glycerol aqueous phase reforming for hydrogen generation over Pt catalyst effect of catalyst composition and reaction conditions. Fuel 87(17-18):3483-3489

Oasmaa A, Kuoppala E, Solantausta Y (2003) Fast pyrolysis of forestry residue. 2. Physicochemical composition of product liquid. Energy Fuels 17(2):433-443

Pütün A, Özbay N, Pütün E (2006) Effect of steam on the pyrolysis of biomass. Energy Sources Part A 28 (3):253-262

Seifert T, Sievers S, Bramsiepe C et al (2012) Small scale, modular and continuous: a new approach in plant design. Chem Eng Process Process Intensif 52:140150

Serrano-Ruiz JC, Luque R, Sepulveda-Escribano A (2011) Transformations of biomass-derived platform 
molecules: from high added-value chemicals to fuels via aqueous-phase processing. Chem Soc Rev 40 (11):5266-5281

Silla H (2003) Chemical process engineering. Design and economics. Chemical Industries. Marcel Dekker, New York

Sinnot R, Towler G, Sinnott RK (2009) Chemical engineering design, 5th edn. Coulson \& Richardson's chemical engineering series. Butterworth-Heinemamn, Oxford

Stoeckel M, Lidolt M, Stressler T et al (2016) Heat stability of indigenous milk plasmin and proteases from Pseudomonas: a challenge in the production of UHT milk products. Int Dairy J 61:250-261. https:// doi.org/10.1016/j.idairyj.2016.06.009

Teong SP, Yi G, Zhang Y (2014) Hydroxymethylfurfural production from bioresources: past, present and future. Green Chem 16(4):2015-2026
Titirici MM, White RJ, Brun N et al (2015a) Sustainable carbon materials. Chem Soc Rev 44(1):250-290

Titirici MM, Funke A, Kruse A (2015b) Hydrothermal carbonization of biomass. Recent advances in thermochemical conversion of biomass. In: Pandey A, Bhaskar T, Stöcker M, Sukumaran R (eds) Recent advances in thermochemical conversion of biomass. Elsevier, Oxford, pp 325-352

Valdez PJ, Vincent JT, Savage PE (2014) A general kinetic model for the hydrothermal liquefaction of microalgae. Bioresour Technol 163(0):123-127

Wildschut J, Mahfud FH, Venderbosch RH et al (2009) Hydrotreatment of fast pyrolysis oil using heterogeneous noble-metal catalysts. Ind Eng Chem Res 48 (23):10324-10334

Yin S, Pan Y, Tan Z (2011) Hydrothermal conversion of cellulose to 5-hydroxymethyl furfural. Int J Green Energy 8(2):234-247

Open Access This chapter is licensed under the terms of the Creative Commons Attribution 4.0 International License (http://creativecommons.org/licenses/by/4.0/), which permits use, sharing, adaptation, distribution and reproduction in any medium or format, as long as you give appropriate credit to the original author(s) and the source, provide a link to the Creative Commons license and indicate if changes were made.

The images or other third party material in this chapter are included in the chapter's Creative Commons license, unless indicated otherwise in a credit line to the material. If material is not included in the chapter's Creative Commons license and your intended use is not permitted by statutory regulation or exceeds the permitted use, you will need to obtain permission directly from the copyright holder. 